\title{
Article
}

\section{Escin-induced DNA damage promotes escin-induced apoptosis in human colorectal cancer cells via p62 regulation of the ATM/ $\mathrm{YH} 2 \mathrm{AX}$ pathway}

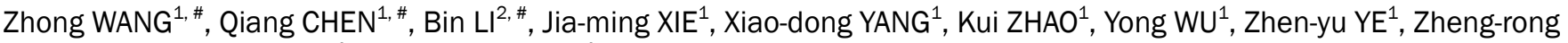 \\ $\mathrm{CHEN}^{1}$, Zheng-hong QIN ${ }^{3, *}$, Chun-gen XING ${ }^{1, *}$ \\ ${ }^{1}$ Department of General Surgery, Second Affiliated Hospital of Soochow University, Suzhou 215007, China; ${ }^{2}$ Department of General \\ Surgery, the First People's Hospital of Wu Jiang, Suzhou 215200, China; ${ }^{3}$ Department of Pharmacology and Laboratory of Aging and \\ Nervous Diseases, Jiangsu Key Laboratory of Translational Research and Therapy for Neuro-Psycho-Diseases, Jiangsu Key Laboratory \\ of Preventive and Translational Medicine for Geriatric Diseases, College of Pharmaceutical Science, Soochow University, Suzhou \\ 215123, China
}

\begin{abstract}
Escin, a triterpene saponin isolated from horse chestnut seed, has been used to treat encephaledema, tissue swelling and chronic venous insufficiency. Recent studies show that escin induces cell cycle arrest, tumor proliferation inhibition and tumor cell apoptosis. But the relationship between escin-induced DNA damage and cell apoptosis in tumor cells remains unclear. In this study, we investigated whether and how escin-induced DNA damage contributed to escin-induced apoptosis in human colorectal cancer cells. Escin $(5-80 \mu \mathrm{g} / \mathrm{mL})$ dose-dependently inhibited the cell viability and colony formation in HCT116 and HCT8 cells. Escin treatment induced DNA damage, leading to p-ATM and $\mathrm{yH} 2 \mathrm{AX}$ upregulation. Meanwhile, escin treatment increased the expression of p62, an adaptor protein, which played a crucial role in controlling cell survival and tumorigenesis, and had a protective effect against escininduced DNA damage: knockdown of p62 apparently enhanced escin-induced DNA damage, whereas overexpression of p62 reduced escin-induced DNA damage. In addition, escin treatment induced concentration- and time-dependent apoptosis. Similarly, knockdown of p62 significantly increased escin-induced apoptosis in vitro and produced an escin-like antitumor effect in vivo. Overexpression of p62 decreased the rate of apoptosis. Further studies revealed that the functions of p62 in escin-induced DNA damage were associated with escin-induced apoptosis, and p62 knockdown combined with the ATM inhibitor KU55933 augmented escin-induced DNA damage and further increased escin-induced apoptosis. In conclusion, our results demonstrate that p62 regulates ATM/YH2AX pathwaymediated escin-induced DNA damage and apoptosis.
\end{abstract}

Keywords: escin, p62, DNA damage, ATM/YH2AX pathway; apoptosis, colorectal cancer; HCT116 cells; HCT8 cells

Acta Pharmacologica Sinica (2018) 39: 1645-1660; doi: 10.1038/aps.2017.192; published online 31 May 2018

\section{Introduction}

Colorectal cancer (CRC), one of the most common malignant tumors of the digestive tract ${ }^{[1]}$, was the third most common cancer and third leading cause of cancer death in the United States in $2014^{[2]}$. Surgery and combination therapy including surgery, chemotherapy and radiotherapy are important treatments for $\mathrm{CRC}$, and chemotherapy plays a vital role in the treatment of CRC. However, the prognosis of CRC patients

\footnotetext{
\# These authors contributed equally to this work.

${ }^{*}$ To whom correspondence should be addressed.

E-mail xingcgchn@163.com (Chun-gen XING); qinzhenhong@suda.edu.cn (Zheng-hong QIN)

Received 2017-09-13 Accepted 2017-12-29
}

is poor, with only a $65 \%$ five-year relative survival rate in $2013^{[3]}$. Multidrug resistance (MDR), an important contributor to the insensitivity of chemotherapy, is crucial in cancer recurrence and metastasis, and leads to poor patient prognosis ${ }^{[4]}$. MDR is perceived to be the primary reason for chemotherapy resistance and is caused by different structures and molecular mechanisms, including overexpression of the ATP-binding cassette $(\mathrm{ABC})$ transporter, DNA damage and repair, mutation of drug targets, activation of survival pathways and autophagy, evasion of apoptosis, epithelial changes and the presence of cancer stem cells ${ }^{[5-7]}$. Hence, novel and effective chemotherapy strategies, including seeking the mechanisms behind MDR and enhancing the effect of chemotherapeutic drugs, are urgently needed for the treatment of CRC. 
Escin, a triterpene saponin isolated from horse chestnut seed, has been applied in the treatment of encephaledema in clinical practice, a condition caused by swelling that results from trauma or surgery and chronic venous insufficiency ${ }^{[8,9]}$. Interestingly, escin has been shown to have an antineoplastic effect by the induction of cell proliferation inhibition and apoptosis in cholangiocarcinoma cells ${ }^{[10]}$, rat embryo fibroblast cells ${ }^{[11]}$, cervical carcinoma and breast cancer cells ${ }^{[12]}$, lung adenocarcinoma and glioma cells ${ }^{[13]}$, pancreatic cancer cells ${ }^{[14]}$ and renal cancer cells ${ }^{[15]}$. Recently, escin was found to induce apoptosis of patient-derived glioblastoma-initiating cells (GIC) and inhibit the stem identity of $\mathrm{GIC}^{[16]}$. Escin inhibits the formation of nicotine-derived nitrosamine ketone (NNK)-induced lung tumors by regulating RhoA/Rock signaling ${ }^{[17]}$. Furthermore, escin has a synergistic effect on cancer cells, similar to the synergistic anti-cancer interaction of escin and gemcitabine in pancreatic cancer that inhibits the activity of NF- $\mathrm{KB}^{[18]}$, and a synergistic inhibitory effect with 5-FU in SMMC-7721 cells that arrests the cell cycle and induces apoptosis-related proteins ${ }^{[19]}$. However, the mechanisms of escin in inhibiting tumor proliferation and its synergistic antitumor effect with chemotherapeutic agents requires further exploration.

The adaptor protein p62, known as SQSTM1, was first identified as an autophagy adaptor. However, increasing evidence has shown that p62 plays a crucial role in controlling cell survival and tumorigenesis ${ }^{[20]}$. High expression of p62 has been detected in many cancers, such as gastrointestinal cancer ${ }^{[21]}$, breast tumors $^{[22,23]}$ and lung adenocarcinoma ${ }^{[24]}$. Additionally, p62 promotes the proliferation of CRC cells in the absence of autophagy activity and functions as a potent prognostic factor in colorectal tumor patients ${ }^{[25]}$. Furthermore, p62 has been demonstrated to induce cisplatin resistance in human ovarian cancer cells by binding ubiquitinated proteins for transport to autophagic degradation ${ }^{[26]}$. These results suggest the importance of p62 in cancer initiation and progression, in which it not only operates as a signaling adaptor and substrate in autophagy but also has an important function in DNA damage and repair ${ }^{[27]}$.

Our results demonstrate that escin concomitantly induces DNA damage and upregulation of p62 in CRC cells. However, the effects of p62 on escin-induced DNA damage and cell apoptosis are unknown. We verified that p62 plays a protective role in escin-induced DNA damage and cell apoptosis. p62 knockdown increased escin-induced DNA damage and cell apoptosis in vitro and the antitumor effect of escin in vivo. Increasing DNA damage contributed to escin-induced apoptosis via p62 regulation of the $\mathrm{ATM} /{ }_{\mathrm{H}} \mathrm{H} 2 \mathrm{AX}$ pathway in $\mathrm{CRC}$ cells.

\section{Materials and methods}

Cell culture and drug treatment

Human CRC cell lines (HCT116 and HCT8) were obtained from Shanghai Chinese Academy Sciences (Shanghai, China). The cells were cultured with Dulbecco's Modified Eagle's Medium (DMEM; GIBCO , C11965500BT, New York, USA) supplemented with $10 \%$ fetal bovine serum (FBS; GIBCO;
10270-106) at $37^{\circ} \mathrm{C}$ in a $5 \% \mathrm{CO}_{2}$ humidified atmosphere. Escin was purchased from Shandong Luye Pharma LTD (Yantai, Shandong, China) and dissolved in normal saline. KU-55933 (ATM Kinase Inhibitor) was purchased from Selleck (S1092, Shanghai, China) and dissolved in dimethylsulfoxide (DMSO, DT0163, Shanghai, China). N-Acetyl-L-cysteine (NAC) was purchased from Sangon Biotech (A601127, Shanghai, China) and dissolved in DMSO.

\section{Measurement of cell viability and proliferation}

The short-term effects of escin, p62 knockdown or p62 overexpression on cell growth were detected by CCK8 (CK043000T, Dojindo, Japan). Cells were seeded at a density of 3000 cells/well in 96-well plates. After a series of treatments were applied to the cells, $10 \mu \mathrm{L}$ of CCK8 was added to each well, and then, the cells were incubated at $37^{\circ} \mathrm{C}$ for $2 \mathrm{~h}$. The absorbance was measured at $450 \mathrm{~nm}$ with a microculture plate reader (Bie Tek). The percentage of growth inhibition was estimated by the absorbance. The long-term effects of escin on cell growth were assessed with a clone formation assay. Cells were cultured at a density of 200 cells per well in 6-well plates for $36 \mathrm{~h}$. Then, different concentrations of escin $(5,10$ and 20 $\mu \mathrm{g} / \mathrm{mL}$ ) were added. Cells were cultured for approximately $14 \mathrm{~d}$ until the cells grew visible colonies. The medium was discarded, and the colonies were stained with crystal violet (C0121, Beyotime) for $15 \mathrm{~min}$ at room temperature. After carefully washing with double distilled water, the colonies were counted and photographed using an iPhone.

\section{Immunofluorescence}

Cells were plated on cover glass in 24-well plates. After a series of treatments, cells were washed with phosphate buffered saline (PBS) 3 times and fixed with precooled methanol for $20 \mathrm{~min}$, followed by permeabilization with $0.2 \%$ Triton- $X$ 100 in PBS for $15 \mathrm{~min}$ at $4{ }^{\circ} \mathrm{C}$. Then, the cells were blocked with $5 \%$ horse serum in PBS for $1 \mathrm{~h}$ at room temperature. The cells were incubated with primary antibody overnight at $4{ }^{\circ} \mathrm{C}$. After washing the cells with $0.05 \%$ Triton-X 100 in PBS for 10 $\min \times 3$ times, they were incubated with 488 -conjugated donkey anti-rabbit IgG (1:1000; Jackson ImmunoResearch Laboratories) for $30 \mathrm{~min}$ at room temperature. After $10 \mathrm{~min}$ of three washes with $0.05 \%$ Triton-X 100 in PBS, the cells were incubated with DAPI for $3 \mathrm{~min}$; then, the cells were dehydrated in increasing grades of ethanol and cover-slipped with Fluoromount Aqueous Mounting Medium (Sigma, F4680; Saint Louis, MO, USA). The slides were analyzed with a laser scanning confocal unit (Zeiss LSM 710, Carl Zeiss, Jena, Germany)

\section{RT-PCR}

Total RNA was extracted from cells by TRIzol reagent (TaKaRa) according to the instructions and then reversetranscribed into cDNA with a TransScript First-Stand cDNA Synthesis Kit (TaKaRa). Real-time quantitative PCR was performed using SYBR Green Mastermix (TaKaRa) on a 7500 real-time PCR system (Applied Biosystems). The primer pairs were as follows: for p62 (forward primer: 5'-TGTG- 
TAGCGTCTGCGAGGGAAA-3', reverse primer: 5'-AGTGTCCGTGTTTCACCTTCCG-3'); for $\beta$-actin (forward primer: 5'-CACCATTGGCAATGAGCGGTTC-3', reverse primer: 5'-AGGTCTTTGCGGATGTCCACGT-3').

\section{siRNA design and transfection}

To inhibit the expression of p62, p62 siRNA1/2 (1\#, 5'-GUGACGAGGAAUUGACAAUTT-3'; 2\#, 5'-GGAGUCGGAUAACUGUUCATT-3 $\left.{ }^{\prime}\right)^{[28]}$ and scramble siRNA (5'-UUCUCCGAACGUGUCACGUTT-3') were obtained from GenePharma Co (Shanghai, China). Cells were plated in 6-well plates (500 000 cells/well) or 96-well plates (3000 cells/well) and were transfected with scramble siRNA or p62 siRNAs using Lipofectamine RNAiMAX (Invitrogen, USA) that was diluted in Opti-MEM Reduced Serum Medium (GIBCO, 31985070). The final concentrations of scramble siRNA and p62 siRNAs were $60 \mathrm{nmol} / \mathrm{L}$. After transfection with different siRNAs, cells were cultured for $36 \mathrm{~h}$. After treatment with escin for 12 $h$, cell viability was tested by the CCK8 assay and the expression of different proteins was detected using Western blotting.

\section{Plasmid construction and transfection}

The FLAG-p62 overexpression plasmid was kindly provided by Prof Hai-gang REN ${ }^{[29]}$ (Paycho-disease and College of Pharmaceutical Sciences, Soochow University, Suzhou, China). Cells were plated in 6-well plates (700 000 cells/well) or 96-well plates (3000 cell/well) and transfected with the FLAGNC or FLAG-p62 plasmids using Lipofectamine 3000 (Invitrogen, USA) that was diluted in Opti-MEM Reduced Serum Medium (GIBCO, 31985070) for $36 \mathrm{~h}$. The final concentration of the FLAG-p62 and FLAG-NC plasmids was $3 \mu \mathrm{g} / \mathrm{mL}$. After transfection with different plasmids, cells were cultured for $36 \mathrm{~h}$. After treatment with escin for $12 \mathrm{~h}$, cell viability was tested by the CCK8 assay and the expression of different proteins was detected by Western blotting.

\section{Western blot analysis and antibodies}

Cell samples were lysed in a cell lysis solution that contained protease inhibitors (Roche, 04693159001) and phosphorylase inhibitors (Roche, 04906845001). The concentrations of cell proteins were assessed with a BCA Protein Assay Kit (TaKaRa, T9300A). Equal amounts of proteins were separated on Trisglycine SDS-polyacrylamide gels and transferred onto an NC membrane. Membranes were blocked in 5\% non-fat milk for $2 \mathrm{~h}$ at room temperature and then incubated with primary antibodies against p-53BP1 (1:200, OmnimAbs, OM212889), p-ATM (1:1000, Abcam, ab81292), ATM (1:1000, Abcam, ab199726), p62 (1:2000, Sigma, P0067), PARP (1:1000, Cell Signaling Technology, \#9532), $\gamma \mathrm{H} 2 \mathrm{AX}$ (1:1000, Cell Signaling Technology, \#9718), cleaved-caspase 9 (1:1000, Cell Signaling Technology, \#9505), or $\beta$-actin (1:10000, Sigma, A5441) in $1 \%$ BSA overnight at $4{ }^{\circ} \mathrm{C}$. After washing in TBST 3 times, membranes were incubated with the appropriate secondary antibodies (1:10000, Odyssey LI-COR, anti-rabbit, 92632213, anti-mouse, 92632212) at room temperature for $2 \mathrm{~h}$. Immunoreactivity was imaged using an Odyssey Infrared Imager (Li-
COR Biosciences, USA) and quantified using Image J software (W S Rasband, Image J, NIH).

\section{Flow cytometry detection of apoptosis and ROS}

Cells were plated in 6-well plates. After a series of treatments, cells were trypsinized and harvested. Then, cells were resuspended in $300 \mu \mathrm{L}$ of binding buffer containing $5 \mu \mathrm{L}$ of propidium iodide (PI) and $5 \mu \mathrm{L}$ of annexin V-FITC (Biouniquer, BU-AP0103) at room temperature for $15 \mathrm{~min}$. The samples were analyzed by a FACScan flow cytometer (FACScan, Becton Dickson).

Cells were seeded onto 6-well plates and incubated for $24 \mathrm{~h}$. Afterwards, different concentrations of escin were added for $12 \mathrm{~h}$. Then, the ROS levels were determined by incubating cells with cell culture medium containing $10 \mathrm{mmol} / \mathrm{L}$ H2-DCFDA for $30 \mathrm{~min}$ at $37^{\circ} \mathrm{C}$. The cells were washed twice in PBS, trypsinized, and resuspended in PBS. The ROS content was measured with FACS (FACScan, Becton Dickinson).

\section{Tumor growth analysis in vivo}

To acquire HCT116 cells with a stable p62 knockdown, cells were transfected with p62-shRNA (5'-GTGACGAGGAATTGACAAT-3'; GenePharma, Shanghai, China), and the expression of green fluorescent protein (GFP) was detected by fluorescence microscopy $36 \mathrm{~h}$ after transfection. Then, cells were selected in medium with $4 \mu \mathrm{g} / \mathrm{mL}$ puromycin for 2 weeks. The expression of p62 was detected via Western blotting, and the cells were cultured for expansion. All experimental procedures were conducted according to the Regulations of Experimental Animal Administration issued by the Animal Committee of Soochow University. Cells (3 000000 in $250 \mu \mathrm{L}$ of PBS) were injected subcutaneously into the right iliac fossa of 6-week-old female athymic nude mice (The Animal Center of Soochow University). After approximately 6 weeks, visible tumors had developed and escin $(2 \mathrm{mg} / \mathrm{kg})$ was intraperitoneally injected every day for 2 weeks. Mice were sacrificed and the tumor tissues were removed. The weight of the tumors was calculated. Tumor tissues were used for Western blotting to evaluate the expression of p62.

\section{Statistical analysis}

All data were analyzed with at least three independent experiments and are presented as the mean \pm SD. GraphPad Prism 6 (GraphPad Software, Inc, La Jolla, CA, USA) was used for statistical analysis by using one-way ANOVA analysis.

\section{Results}

\section{Escin inhibited proliferation of CRC cells}

To verify the short-term effect of escin-induced growth inhibition of human CRC HCT116 and HCT8 cells, cells were treated with different concentrations of escin $(0-100 \mu \mathrm{g} / \mathrm{mL})$ for 12 , 24 or $48 \mathrm{~h}$, and cell viability was measured by the CCK8 assay. As shown in Figure 1A-B, escin inhibited the proliferation of two CRC cell lines in a time- and concentration-dependent manner. A long-term proliferation inhibition effect was observed with a colony formation assay, which indicated that 

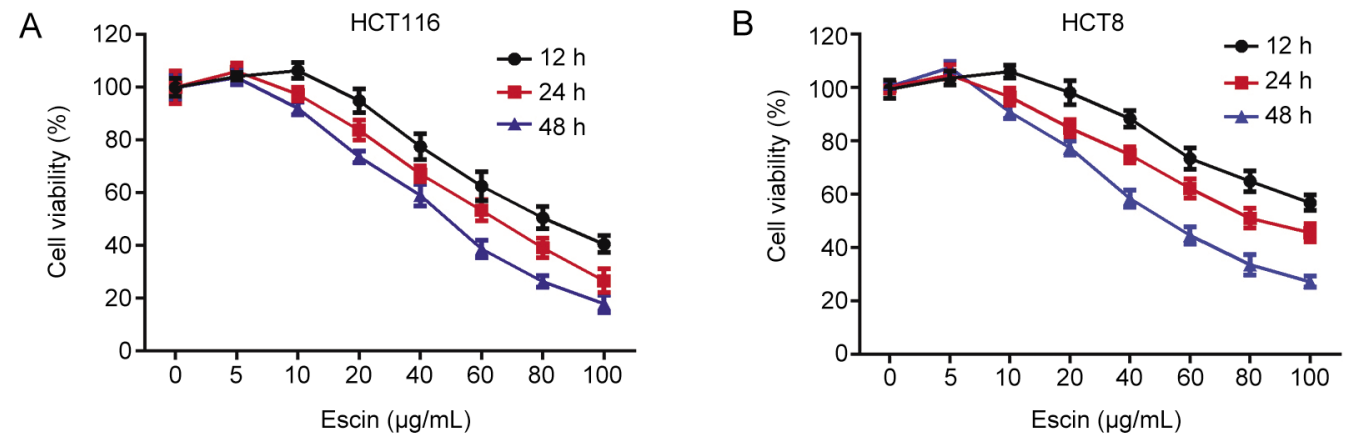

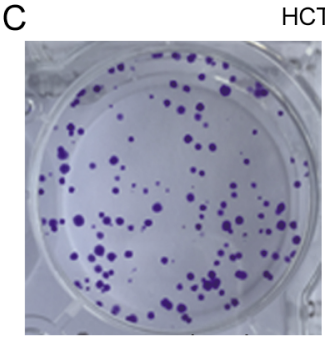

0

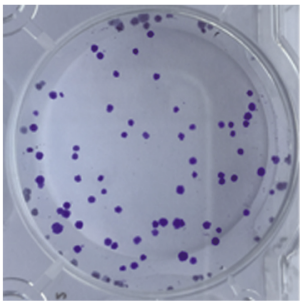

10

$\mathrm{E}$

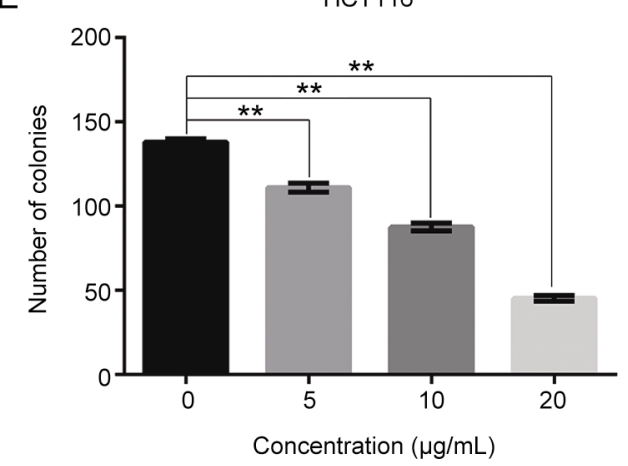

D
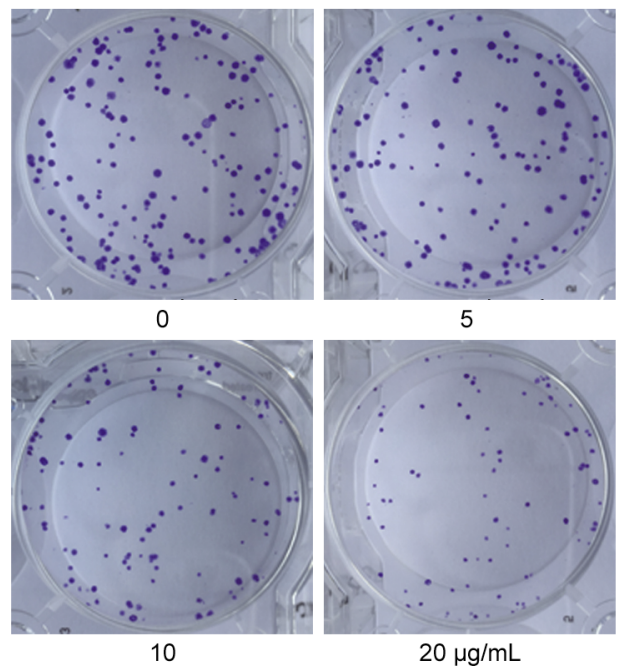

$\mathrm{F}$

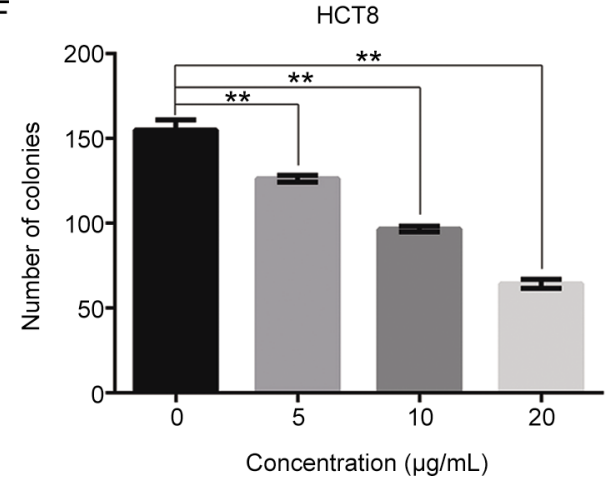

Figure 1. Escin inhibited proliferation in HCT116 and HCT8 cells. (A, B) Cells were treated with a series of concentrations of escin $(0-100 \mu g / m L)$ for 12,24 or $48 \mathrm{~h}$, and cell viability was measured by the CCK8 assay. (C, D) A total of 200 cells were seeded in 6-well plates and cultivated for $12-14 \mathrm{~d}$. Colony formation was detected. (E, F) Quantitative analysis of the colony numbers of HCT116 and HCT8 cells after escin treatment. The values are the mean \pm SD from three independent experiments. ${ }^{* *} P<0.01$ vs the control group.

escin significantly reduced the number of colonies (Figure 1CF). These results suggest that escin inhibits CRC cell proliferation.

\section{Escin induced DNA damage and p62 upregulation}

Because escin induces reactive oxygen species (ROS) generation $^{[15]}$ (Figure 2A) and ROS activates DNA damage responses ${ }^{[30]}$, we speculated that escin probably induced DNA damage. To verify this assumption, we examined the effect of escin on inducing DNA damage responses. As shown in Figure 2B-D, expression of $\gamma \mathrm{H} 2 \mathrm{AX}$, which is a sensitive indicator of the DNA damage response and can indicate variations in DNA damage levels, and p-ATM were increased in a concentration- and time-dependent manner, while p-53BP1 was upregulated in a concentration-dependent manner. Escininduced DNA damage was further confirmed by immunofluorescence. Consistent with the Western blotting results, escin robustly elevated the levels of $\gamma \mathrm{H} 2 \mathrm{AX}$ in nucleus (Figure 


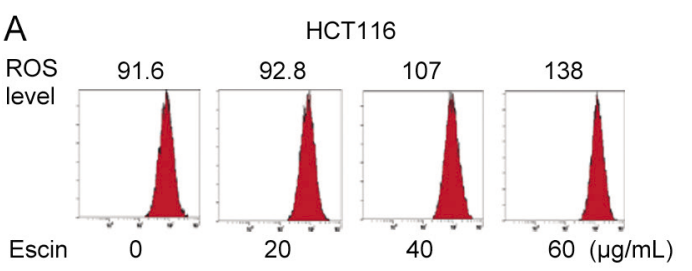

C $\begin{array}{lllllll}\text { Escin } & 0 & 5 & 10 & 20 & 40 & 80\end{array}$ p-ATM $=24=20$
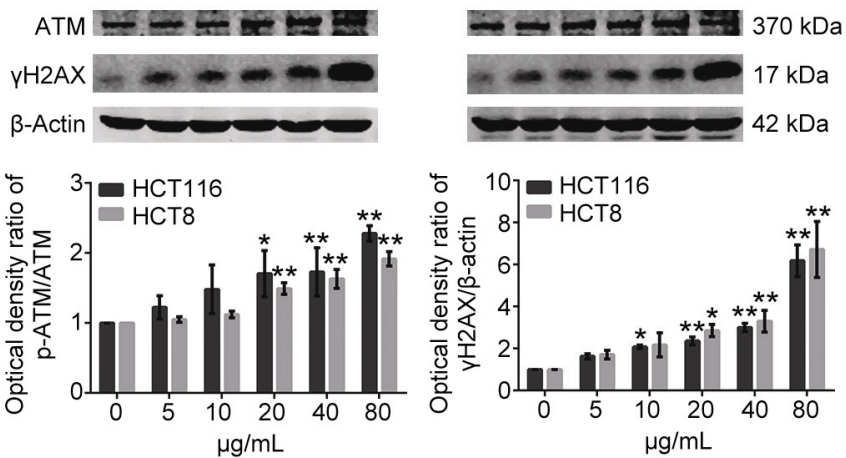

E
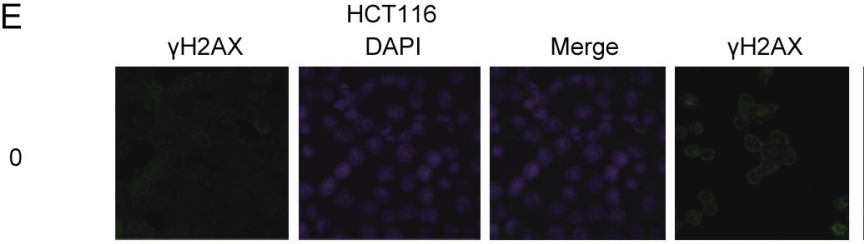

20
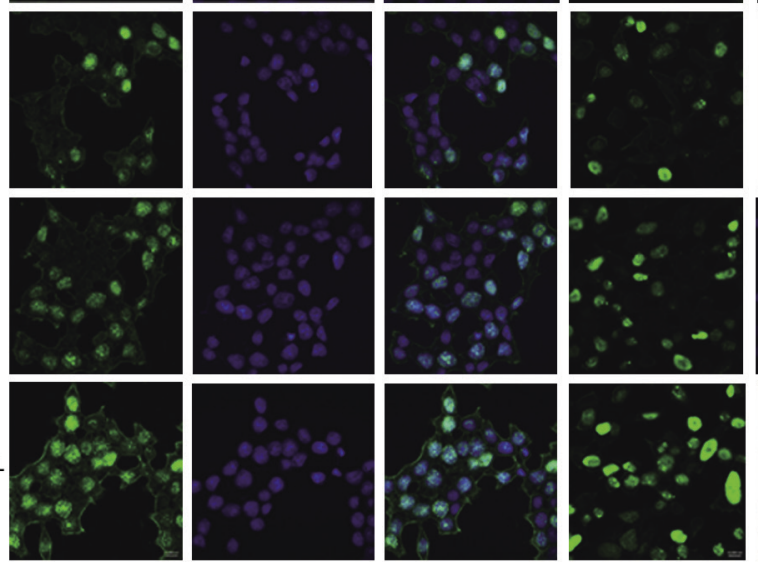
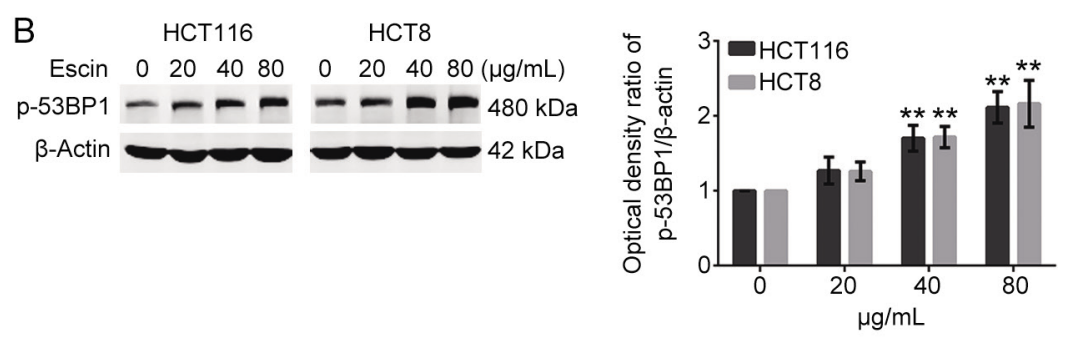

D

$\begin{array}{lllllll}\text { Time } & 0 & 3 & 6 & 9 & 12 & 24\end{array}$

p-ATM $=----=$

ATM $-==-=$

$\mathrm{YH} 2 \mathrm{AX} \quad-00$
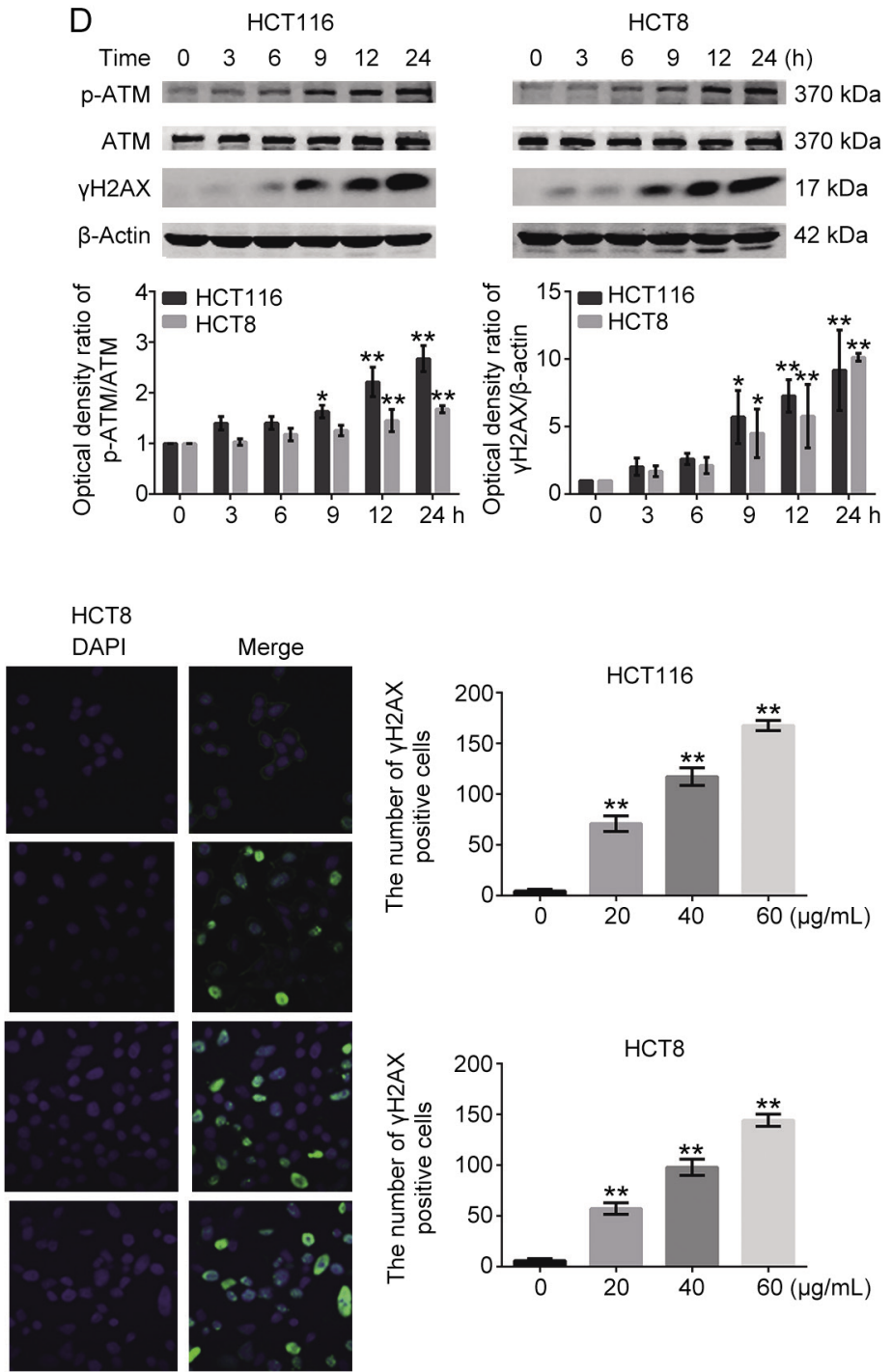

Figure 2A-2E. Escin induced DNA damage and upregulation of p62. Cells were treated with different concentrations of escin for $12 \mathrm{~h}$ or treated with $60 \mu \mathrm{g} / \mathrm{mL}$ escin for 3, 6, 9, 12 and $24 \mathrm{~h}$. (A) Escin induced ROS generation. HCT16 cells were treated with different concentrations of escin, and the level of ROS was determined by FACS. (B, C, D) The protein levels of p-53BP1, p-ATM, ATM, yH2AX, and $\beta$-actin were detected by Western blotting. Right and down: quantitative analysis of the optical density ratio of p-53BP1, p-ATM, yH2AX compared with the loading control ( $\beta$-actin) in HCT116 and HCT8. (E) Distribution of $\mathrm{YH} 2 \mathrm{AX}$ in HCT116 and HCT8 cells treated as described above that were analyzed with confocal microscopy. $\mathrm{YH} 2 \mathrm{AX}$ is stained red, and the nucleus is stained blue. Scale bar=10 $\mu \mathrm{m}$. Right: the number of $\mathrm{YH} 2 \mathrm{AX}$ positive cells determined by automated fluorescent object counting was plotted for the control, $n=250$. ${ }^{\text {ns }} P>0.05,{ }^{*} P<0.05,{ }^{* *} P<0.01$ vs the control group.

2E). p62 regulates DNA repair and tumorigenesis ${ }^{[30]}$. Next, we investigated whether p62 participated in the DNA damage response in escin treated cells. The concentration-course study showed that p62 was elevated at concentrations of 20 and $40 \mu \mathrm{g} / \mathrm{mL}$ escin, but returned to the control level at a concentration of $80 \mu \mathrm{g} / \mathrm{mL}$ escin. Similarly, an increase of p62 was observed to occur in a time-dependent manner in the time-course study (Figure 2F). Furthermore, escin-induced p62 upregulation occurred at the transcriptional level (Figure $2 \mathrm{G}$ ) and was eliminated by NAC (Figure $2 \mathrm{H}$ ). These results 

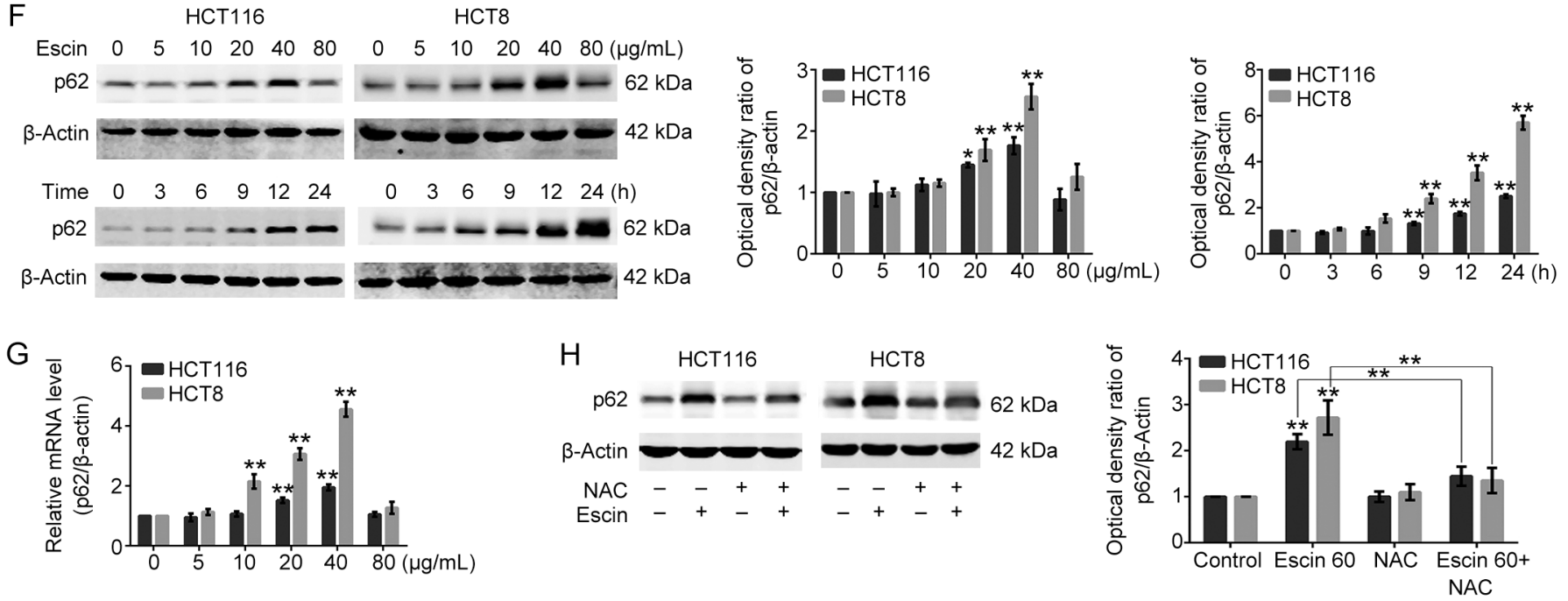

Figure 2F-2H. (F, G) Expression of escin-induced p62 detected by real-time RT-PCR. (H) Cells were pretreated with NAC (ROS scavenger, 5 mmol/L) for $4 \mathrm{~h}$ and then treated with $60 \mu \mathrm{g} / \mathrm{mL}$ escin for $12 \mathrm{~h}$. p62 was analyzed by Western blotting. Right: quantitative analysis of the optical density ratio of p62 compared with the loading control ( $\beta$-actin) in HCT116 and HCT8. The values are the mean $\pm S D$ from three independent experiments. ${ }^{\text {ns }} P>0.05$, ${ }^{*} P<0.05,{ }^{* *} P<0.01$ vs the control group.

indicate that escin induced DNA damage and upregulation of p62 at the same time and, moreover, that the upregulation of p62 was partly attributable to ROS.

\section{p62 protected DNA from escin-induced DNA damage}

As p62 plays an important role in DNA damage and repair and because we concurrently found that escin induces DNA damage and upregulation of p62, the next step was to illustrate the functions of p62 in escin-induced DNA damage responses. To assess the effect of p62 in downregulation, two different p62 siRNAs were used to mediate $\mathrm{p} 62$ suppression in HCT116 and HCT8 cells. Scramble siRNA was used as the negative control. Cells were transfected with scramble siRNA, p62 siRNA1 or p62 siRNA2 at a concentration of $60 \mathrm{nmol} / \mathrm{L}$ for $36 \mathrm{~h}$. The results showed that p62 siRNA1 and siRNA2 apparently downregulated the expression of p62 compared with the negative control in two cell lines, as was detected by Western blotting. There was an $85 \%$ and $81 \%$ silencing efficiency in HCT116 and 95\% and 93\% silencing efficiency in HCT8, respectively (Figure 3A-B). DNA damage related proteins after p62 knockdown with or without treatment of escin were detected by Western blotting. As shown in Figure 3C-F, knockdown of p62 alone had no effect on p-ATM and $\gamma \mathrm{H} 2 \mathrm{AX}$, whereas knockdown of p62 by escin treatment significantly upregulated the levels of $\mathrm{p}-\mathrm{ATM}$ and $\mathrm{\gamma H} 2 \mathrm{AX}$, suggesting a protective role of $\mathrm{p} 62$ in escin-induced DNA damage.

To further confirm the protective role of p62 in escininduced DNA damage, p62 was overexpressed after transfection with the p62 plasmid. Cells were transfected with the FLAG-NC or FLAG-p62 plasmid at a concentration of 3 $\mu \mathrm{g} / \mathrm{mL}$ for $36 \mathrm{~h}$. P62 was successfully overexpressed in two cell lines, as shown by Western blotting, with a fourteen times overexpression efficiency in HCT116 and two-fold overexpression efficiency in HCT8 (Figure 3G-H). Overexpression of p62 alone had no significant effect on p-ATM and $\gamma \mathrm{H} 2 \mathrm{AX}$. Conversely, overexpression of $\mathrm{p} 62$ dramatically downregulated the levels of p-ATM and $\gamma \mathrm{H} 2 \mathrm{AX}$ in two cell lines with escin treatment (Figure 3I-J). These findings indicate that p62 has a significantly protective function in escin-reduced DNA damage.

\section{Escin induced cell apoptosis}

Severe DNA damage may lead to apoptosis. Escin induced cell DNA damage, which may have resulted in apoptosis. We next examined the effect of escin on apoptosis via flow cytometry analysis (FACS). The results demonstrated that escin induced apoptosis in a concentration-dependent manner in two cell lines (Figure 4A-B). We also detected the expression of apoptosis related proteins by Western blotting. The expression levels of cleaved-poly (ADP-ribose) polymerase (c-PARP) and cleaved-caspase 9 (c-Casp 9) were strikingly increased after cells were treated with high concentrations of escin or were exposed for to escin at a $60 \mathrm{\mu g} / \mathrm{mL}$ concentration for a long time (Figure 4C-F). All of these results suggest that escin induced cell apoptosis in a concentration- and time-dependent manner.

\section{Downregulation of p62 enhanced escin-induced cell apoptosis}

Escin induced p62 upregulation and induced cell apoptosis at the same time. To verify any role of p62 in escin-induced apoptosis, we performed a cell growth assay and apoptosisrelated experiments to examine cell viability and apoptosis. Cell viability measured by CCK8 showed that knockdown of p62 alone had no effect on cell viability. However, cell viability was markedly decreased in cells with the p62 knockdown that were treated with escin compared to cells that were scramble siRNA transfected and received an escin treatment, indicating a protective role of p62 in cell survival (Figure 5AB). Furthermore, p62 knockdown and escin treatment greatly increased the rate of HCT116 apoptosis compared with those 
A

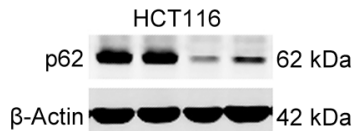

Control + - - Scr SiRNA - + p62 SiRNA1 - - + p62 SiRNA2 - $-\quad+$

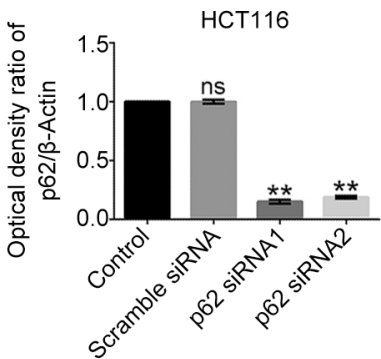

B

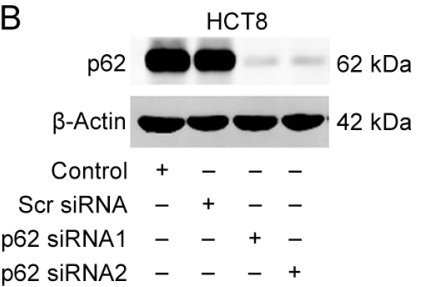

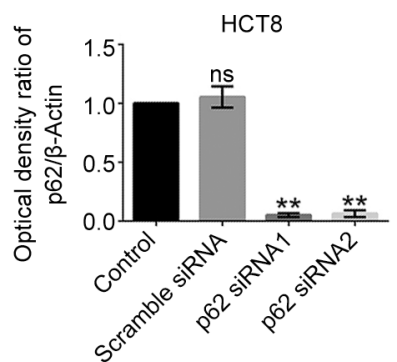

C

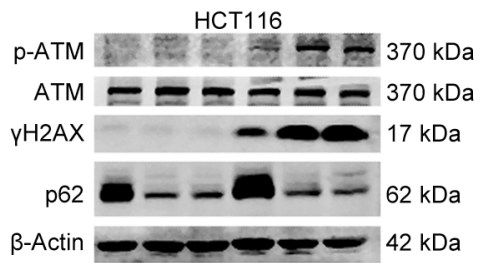

Scr SiRNA + - - + -

p62 siRNA1 - + - - + -

p62 siRNA2 - $-+-\quad+$

Escin $60 \mu \mathrm{g} / \mathrm{mL}-{ }_{-}+++$

E

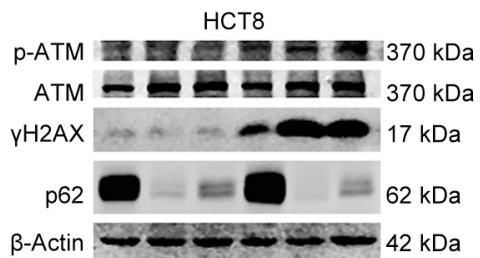

Scr siRNA + - - + -

p62 siRNA1 - + - - + -

p62 siRNA2 - $-+\ldots+$

Escin $60 \mu \mathrm{g} / \mathrm{mL}-{ }_{-}+++$
D

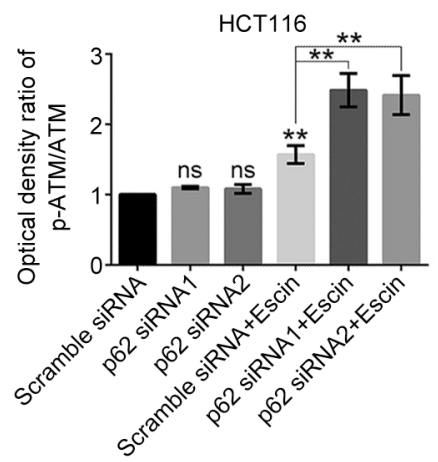

F

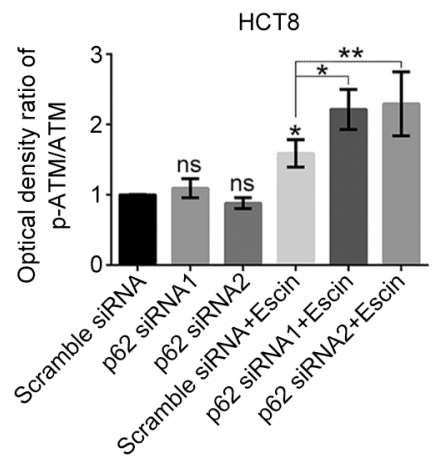

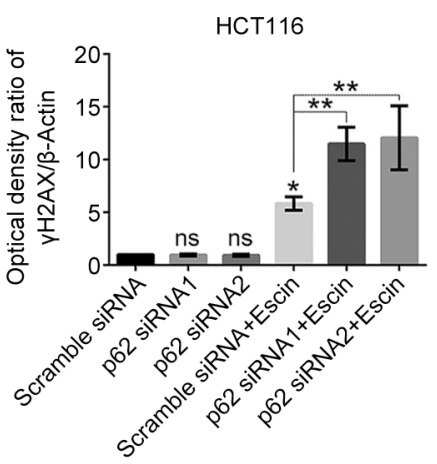

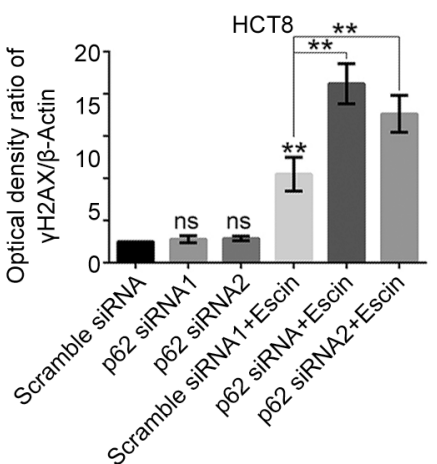

Figure 3A-3F. p62 protected DNA from escin-induced DNA damage. (A, B) Knockdown efficiency of p62 in HCT116 and HCT8 cells. Cells were transiently transfected with scramble siRNA and p62 siRNA1/2 for $36 \mathrm{~h}$. The expression level of p62 was tested by Western blotting. Quantitative analysis of the optical density ratio of p62 compared with $\beta$-actin is shown. (C-F) Expression of DNA damage related proteins after p62 knockdown with escin treatment. Cells were treated with $60 \mu \mathrm{g} / \mathrm{mL}$ escin for $12 \mathrm{~h}$ after scramble siRNA and $\mathrm{p} 62$ siRNA1/2 transfection for $36 \mathrm{~h}$. The protein levels of p-ATM, ATM, $\mathrm{YH} 2 \mathrm{AX}, \mathrm{p} 62$ and $\beta$-actin were detected by Western blotting ( $\mathrm{C}$ and E). Quantitative analysis of the optical density ratio of p-ATM and $\mathrm{yH} 2 \mathrm{AX}$ compared with $\beta$-actin is shown ( $D$ and $F$ ).

treated with scramble siRNA transfection and escin (Figure 5C-D). Consistent with the results of FACS, Western blotting showed that the levels of cleaved-PARP and cleaved-caspase 9 were higher in p62 knockdown and escin-treated cells than in scramble siRNA transfection and escin-treated cells (Figure $5 \mathrm{E}-\mathrm{H})$. The enhancement of apoptosis in cells with p62 knockdown and escin treatment may be attributed to the augmentation of DNA damage.

\section{Overexpression of $\mathrm{p} 62$ attenuated escin-induced cell apoptosis}

To further confirm the anti-apoptosis effect of p62, p62 was overexpressed to detect cell viability and the expression of apoptosis-related proteins. Escin apparently inhibited cell viability, while p62 overexpression rescued the inhibition in two cell lines (Figure 6A). Furthermore, p62 overexpression with escin treatment dramatically decreased HCT116 apoptosis compared with those treated with escin alone (Figure 6B). Consistent with the cell viability and FACS results, p62 overexpression remarkably suppressed the expression of cleavedPARP and cleaved-caspase 9 (Figure 6C-D). p62 not only protected DNA from DNA damage but also antagonized cell apoptosis. These results indicate that p62 obviously reduced escin-induced cell viability inhibition and apoptosis, which is consistent with previous reports of p62 promoting tumorigenesis $^{[31]}$ and multidrug resistance ${ }^{[26]}$.

\section{Downregulation of p62 enhanced the antitumor effect of escin in vivo}

To assess the function of p62 in the escin antitumor effect in vivo, xenografts of HCT116 cells transfected with vector or p62 

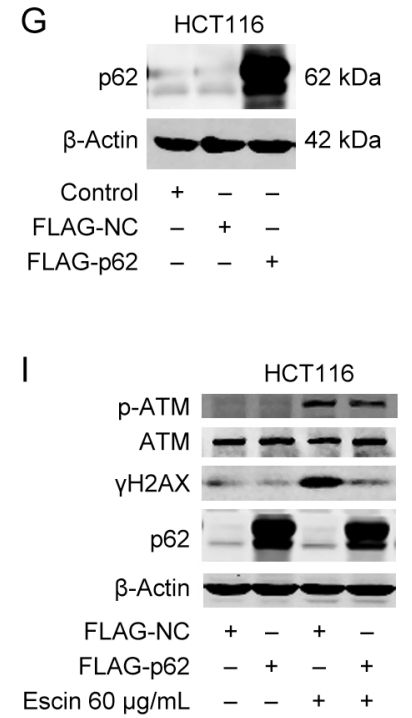
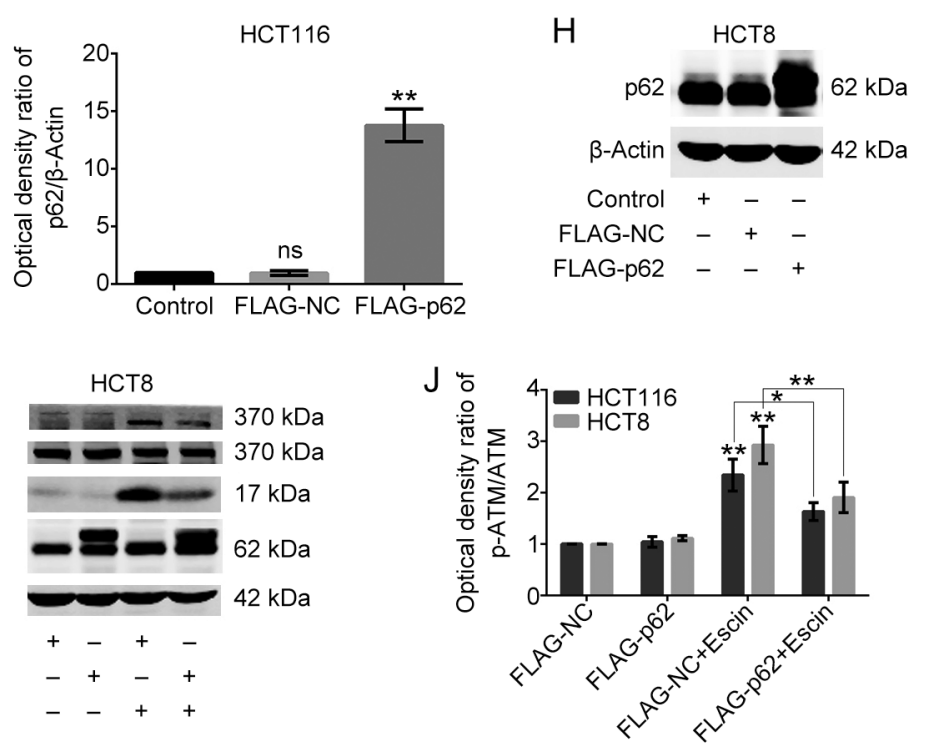

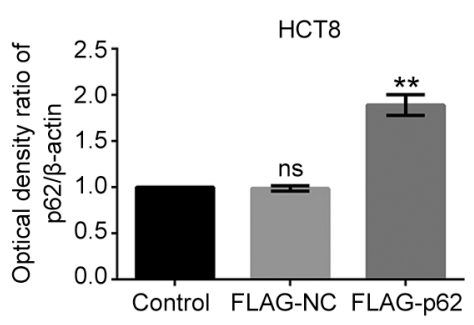

Figure 3G-3J. (G-H) Overexpression efficiency of p62 in HCT116 and HCT8 cells. Cells were transfected with FLAG-p62 plasmids for 36 h. Analysis of p62 expression by Western blotting. Quantitative analysis of the optical density ratio of p62 compared with $\beta$-actin is shown. (I, J) Expression of DNA damage related proteins after p62 overexpression with escin treatment. Cells were treated with $60 \mu \mathrm{g} / \mathrm{mL}$ escin for $12 \mathrm{~h}$ after p62 overexpression plasmid transfection for $36 \mathrm{~h}$. The protein levels of p-ATM, ATM, yH2AX, p62 and $\beta$-actin were detected by Western blotting (I). Quantitative analysis of the optical density ratio of $\mathrm{p}$-ATM and $\mathrm{yH} 2 \mathrm{AX}$ compared with $\beta$-actin is shown $(\mathrm{J})$. The values are the mean $\pm \mathrm{SD}$ from three independent experiments. ${ }^{\text {ns }} P>0.05,{ }^{*} P<0.05,{ }^{* *} P<0.01$ vs the corresponding group.

shRNA were examined. HCT116 cells with a stably expressed vector or p62 shRNA were successfully established (Figure 7A-B). The cells were injected subcutaneously into the right iliac fossa of 6 -week-old female athymic nude mice. These mice were separated into four groups after visible tumor development. The tumor tissues were removed, and the weight of the tumors was calculated after escin $(2 \mathrm{mg} / \mathrm{kg})$ was intraperitoneally injected into mice every day for 2 weeks. As shown in Figure 7C-D, the p62 knockdown group showed a slight inhibition of tumor growth as measured by weight in comparison with the vector group, which indicated that p62 enhanced tumor proliferation. In addition, the vector with escin treatment group inhibited the growth of tumors. Furthermore, the p62 knockdown with escin treatment group achieved a more pronounced inhibition of cell growth than the vector with escin treatment group, which indicated that p62 knockdown enhanced the antitumor effect of escin in vivo. Expression of p62 in xenograft tumor tissues was detected to confirm the downregulation of p62 (Figure 7E).

p62 regulation of the ATM/ $\mathrm{YH} 2 \mathrm{AX}$ pathway was involved in escininduced DNA damage and apoptosis

To verify the potential molecular mechanisms by which p62 reduced escin-induced DNA damage and apoptosis, an ATM specific inhibitor, KU55933, was used to illustrate the function of the ATM $/{ } \mathrm{H} 2 \mathrm{AX}$ pathway in this process. Scramble siRNA, p62 siRNA1 and p62 siRNA2 were transfected for $36 \mathrm{~h}$, and then, KU55933 was applied for $2 \mathrm{~h}$ before escin treatment for $12 \mathrm{~h}$. As shown in Figure 8A-B, p62 knockdown with escin treatment increased the expression of p-ATM,
cleaved-PARP, cleaved-caspase 9 and $\gamma \mathrm{H} 2 \mathrm{AX}$. When all cells were incubated with escin, p62 knockdown with KU55933 significantly increased the levels of cell apoptosis proteins and decreased the level of $\mathrm{\gamma H} 2 \mathrm{AX}$ in comparison with p62 knockdown individually, as shown in Figure 8A-B. There was upregulation of apoptosis-related proteins cleaved-PARP and cleaved-caspase 9, and downregulation of DNA damagerelated protein $\mathrm{\gamma H} 2 \mathrm{AX}$ in the two cell lines. Similarly, the flow cytometry results of the HCT116 cells showed the same outcomes for apoptosis (Figure 8C-D). These results suggest that inhibition of DNA repair, which was induced by KU55933 and p62 knockdown, increased escin-induced apoptosis. The protective functions of $\mathrm{p} 62$ in escin-induced DNA damage attenuated apoptosis by regulating the ATM/ $\gamma \mathrm{H} 2 \mathrm{AX}$ pathway.

In summary, the results of the ATM inhibitor experiment suggested that the degree of DNA damage induced by p62 knockdown was involved in escin-induced apoptosis. P62 modulated escin-induced apoptosis by monitoring DNA damage and repair as well as by regulating the ATM/ $\gamma \mathrm{H} 2 \mathrm{AX}$ pathway.

\section{Escin activated autophagy and inhibition of autophagy augmented escin-induced apoptosis}

Escin elevated the level of ROS in Figure 2a, which is a key upstream signaling to activate autophagy. We next examined the level of cellular autophagy in response to escin. The results showed that escin markedly increased the level of LC3II in a concentration-dependent manner in two cell lines (Figure 9A). Next, we investigated the role of autophagy in escininduced apoptosis. Atg5 siRNA was used to suppress autoph- 
A
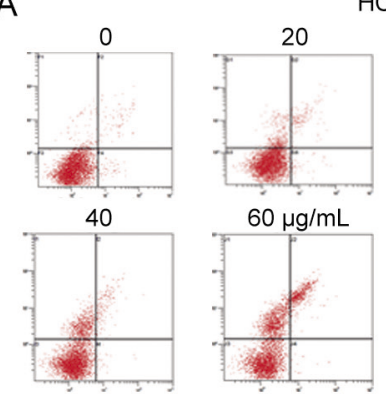

$60 \mu \mathrm{g} / \mathrm{mL}$

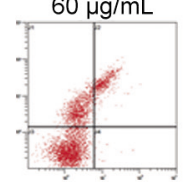

C

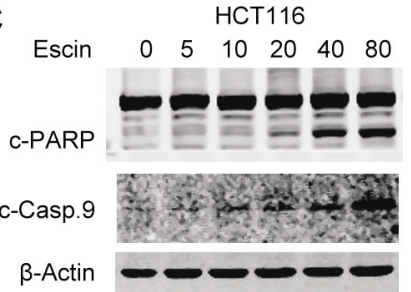

HCT116

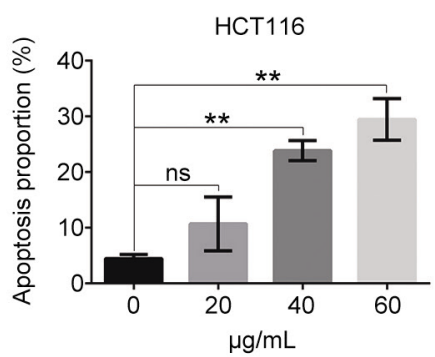

HCT8

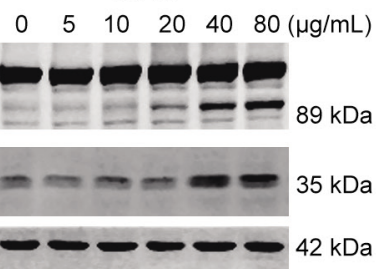

B
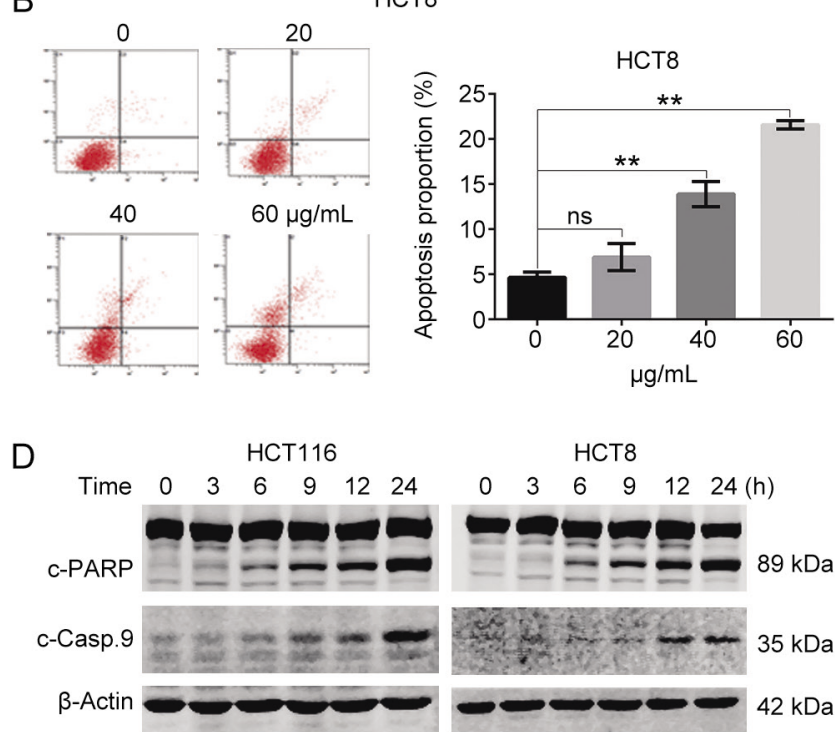

HCT8 $\begin{array}{llllll}0 & 3 & 6 & 9 & 12 & 24\end{array}(\mathrm{~h})$

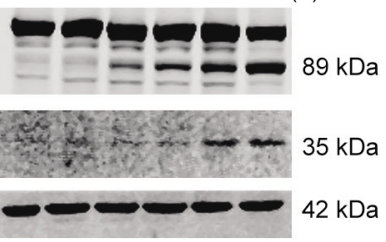

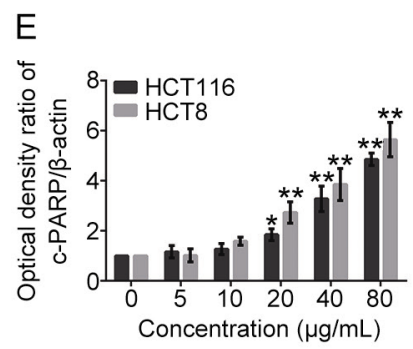
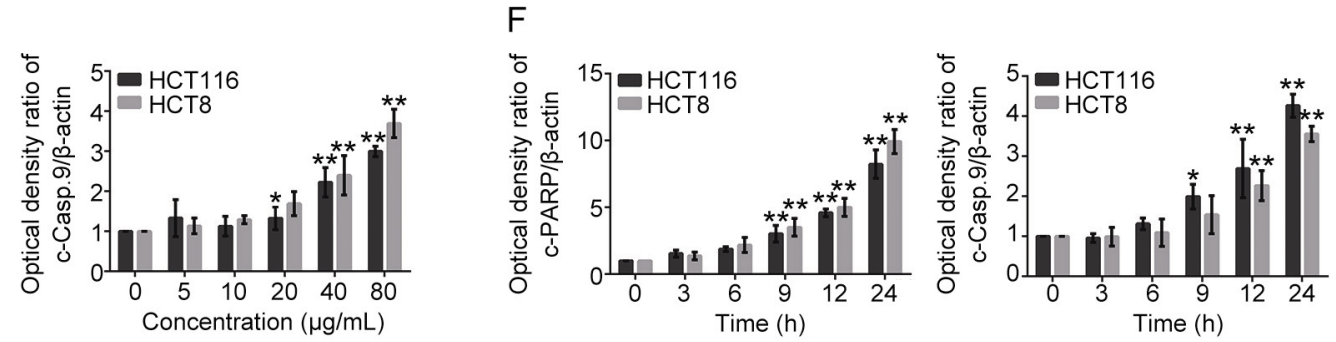

Figure 4. Escin induced apoptosis. (A, B) Escin induced apoptosis. Cells were treated with escin for $12 \mathrm{~h}$, and apoptosis was analyzed by FACS. Quantitative analysis of apoptosis is shown. (C-F) Escin induced upregulation of apoptosis related proteins. Cells were incubated with different concentrations of escin for $12 \mathrm{~h}$ or treated with $60 \mu \mathrm{g} / \mathrm{mL}$ of escin for 3, 6, 9, 12 and $24 \mathrm{~h}$. Apoptosis related proteins (cleaved-PARP and cleavedcaspase 9) were detected by Western blotting ( $C$ and $D$ ). Quantitative analysis of the optical density ratio of cleaved-PARP and cleaved-caspase 9 compared with $\beta$-actin is shown (E, F). The values are the mean \pm SD from three independent experiments. ${ }^{\text {ns }} P>0.05,{ }^{*} P<0.05$, ${ }^{* * *} P<0.01$ vs the control group.

agy in HCT116 and HCT8 cells. As shown in Figure 9B, Atg5 siRNA markedly down-regulated the expression of Atg5 compared with the negative control in two cell lines. Furthermore, inhibition of autophagy with escin treatment for $12 \mathrm{~h}$ significantly increased the protein levels of cleaved-PARP, cleavedcaspase 9 and $\gamma \mathrm{H} 2 \mathrm{AX}$ (Figure 9C). These results suggested that a protective role of autophagy in escin-induced apoptosis and DNA damage. Inhibition of autophagy activity enhanced the antitumor effect of escin.

\section{Discussion}

Chemotherapy is one of the most important treatments for human CRC. However, chemo-resistance, including multidrug resistance (MDR) and insensitivity to clinical antitumor drugs, contributes to the poor prognosis of cancer ${ }^{[2,33]}$. Escin has been reported to inhibit the growth of many cancer cell lines ${ }^{[13,34,35]}$. Consistent with inhibition of tumor proliferation $^{[34]}$ and induction of cell cycle arrest ${ }^{[15]}$, the same inhibitory action of escin was found in vitro (Figure 1) and in vivo (Figure 7). Escin is an inducer of apoptosis ${ }^{[36,37]}$ and operates by inhibiting activation of the JAK/STAT signaling pathway ${ }^{[38]}$. Escin also has an anti-tumor effect that operates by inhibiting NF-KB phosphorylation and nuclear translocation, which affects the expression of its downstream genes and proteins ${ }^{[39]}$. However, whether the mechanisms of escin induction of apoptosis involved DNA damage and repair are still unclear.

Severe DNA damage activates ATM or ATR, followed closely by phosphorylation of various downstream signaling pathway proteins, such as CHK1, CHK2 and $\mathrm{p} 53^{[40,41]}$. Activated ATM phosphorylates $\gamma \mathrm{H} 2 \mathrm{~A} X^{[42,43]}$, which forms a focus that recruits DNA repair proteins around the damage site ${ }^{[42]}$. In addition, inhibition of ATM phosphorylation increases cellular sensitivity to PARP inhibitors in various cell lines ${ }^{[44-46]}$. These studies showed the relationship between DNA damage and apoptosis.

In this study, escin was found to induce DNA damage, as shown by the upregulation of p-ATM and $\gamma \mathrm{H} 2 \mathrm{AX}$, and increase of p62. Furthermore, expression analysis of p-ATM, $\gamma \mathrm{H} 2 \mathrm{AX}$ and p62 suggested that escin-induced DNA damage and upregulation of p62 occurred in a concentration- and time-dependent manner (Figure 2). Severe DNA damage was detected after p62 knockdown along with escin treatment 


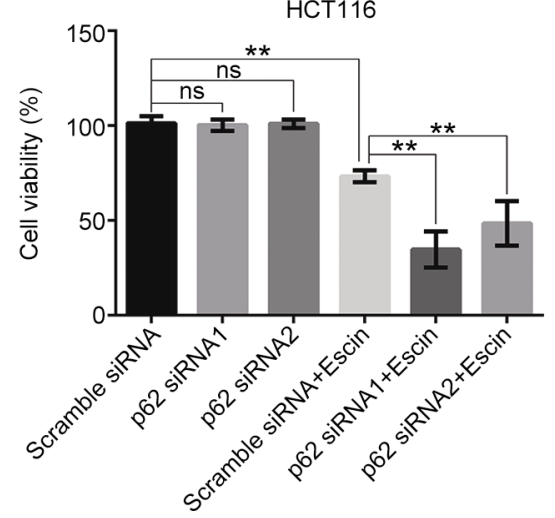

C

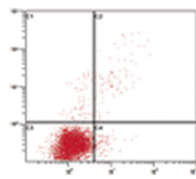

Scramble siRNA

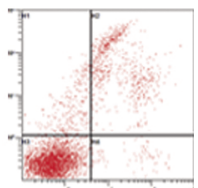

Scramble siRNA+Escin
HCT116

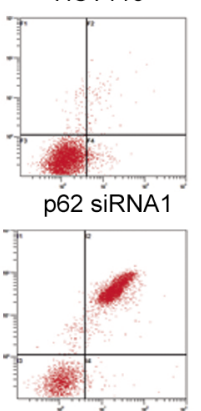

p62 siRNA1+Escin
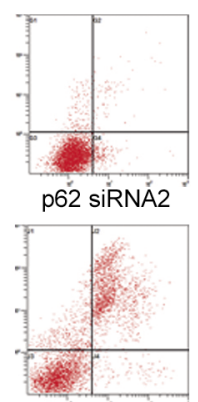

p62 siRNA2+Escin
E

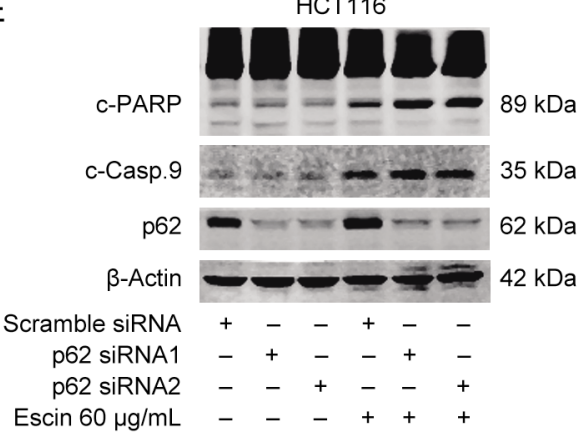

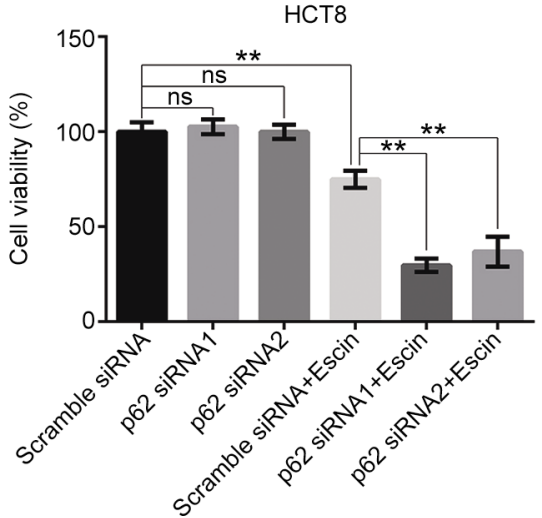

D

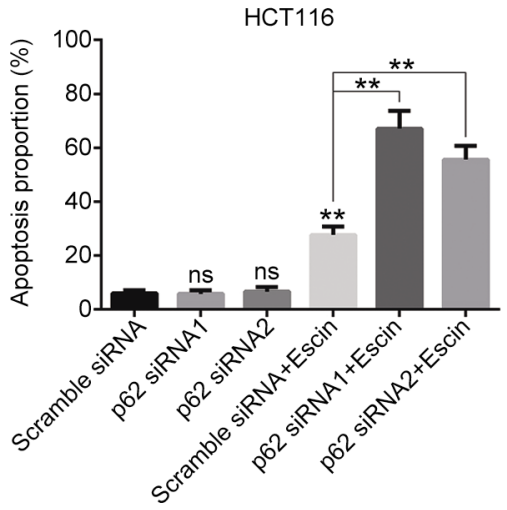

F

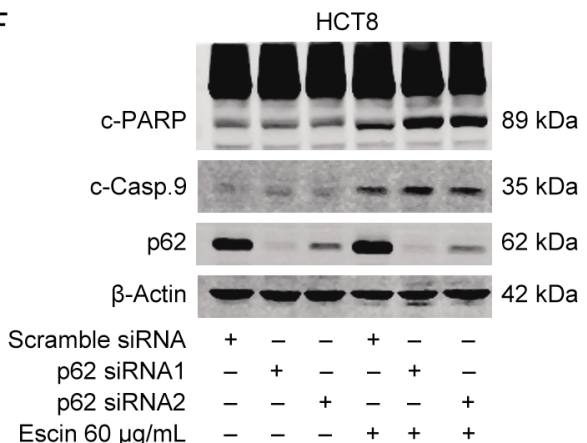

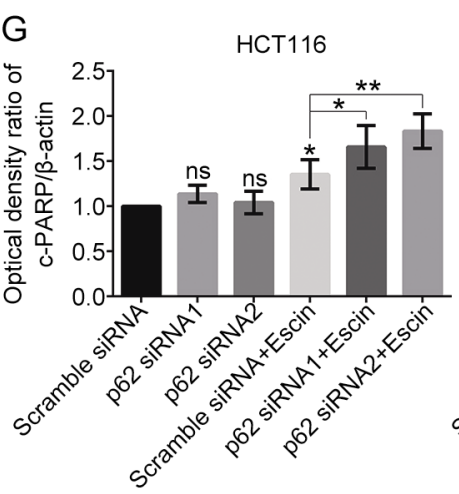
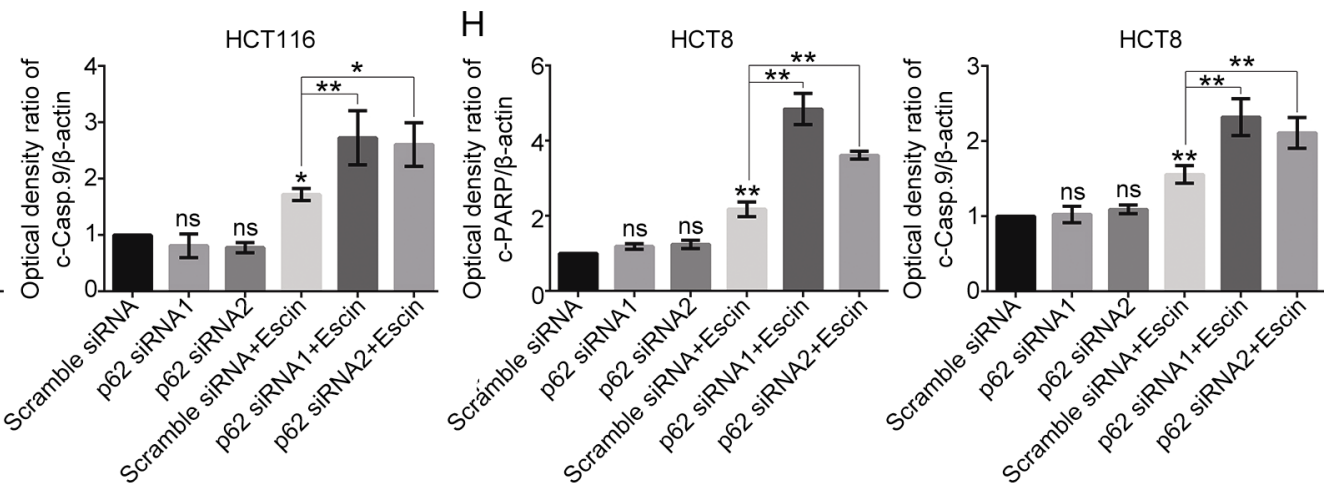

Figure 5. Downregulation of p62 enhanced escin-induced cell apoptosis. (A, B) The effect of escin on cell viability after p62 knockdown. Cells were transiently transfected with scramble siRNA or p62 siRNA1/2 for $36 \mathrm{~h}$ and then treated with $60 \mu \mathrm{g} / \mathrm{mL}$ escin for $12 \mathrm{~h}$. Cell viability was assessed by CCK8 assay. (C, D) Analysis of apoptosis with FACS in HCT116 cells. Cells were treated as described above, and apoptosis was analyzed with FACS. Quantitative analysis of apoptosis after p62 knockdown with or without treatment of escin is shown (D). (E-H) Expression of apoptosis related proteins. Cells were treated as described above, and apoptosis-related proteins were detected with Western blotting (E and F). Quantitative analysis of the optical density ratio of cleaved-PARP and cleaved-caspase 9 compared with $\beta$-actin is shown (G and $H)$. ${ }^{\text {ns }} P>0.05,{ }^{*} P<0.05,{ }^{* *} P<0.01$ vs the corresponding group. 
A

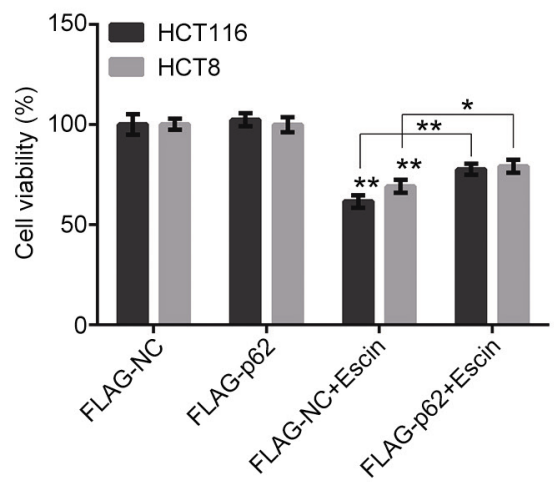

C

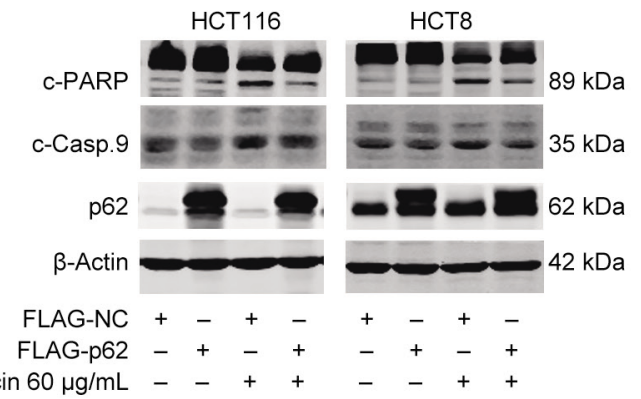

B
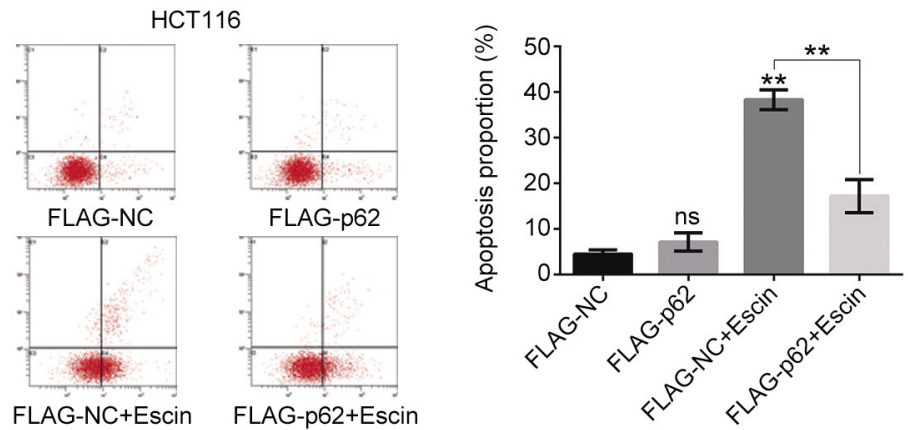

D

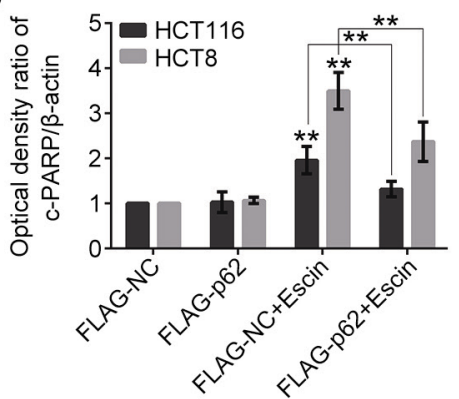

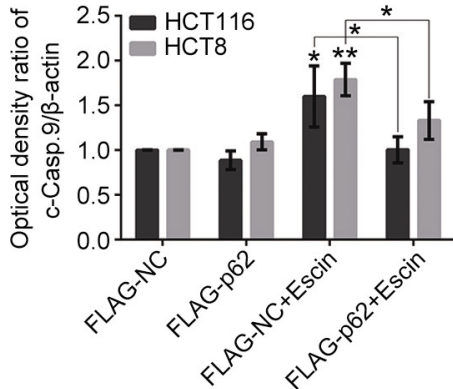

Figure 6. Overexpression of p62 attenuated escin-induced cell apoptosis. (A) The effects of escin on cell viability after p62 overexpression. Cells were transiently transfected with FLAG-NC and FLAG-p62 for $36 \mathrm{~h}$ and then treated with $60 \mu \mathrm{g} / \mathrm{mL}$ escin for $12 \mathrm{~h}$. Cell viability was assessed by the CCK8 assay. (B) Analysis of apoptosis with FACS in HCT116 cells. Cells were treated as described above, and apoptosis was analyzed with FACS. Right: quantitative analysis of apoptosis after p62 overexpression with or without treatment of escin is shown. (C, D) Expression of apoptosis related proteins. Cells were treated as described above, and apoptosis-related proteins were detected by Western blotting (C). Quantitative analysis of the optical density ratio of cleaved-PARP and cleaved-caspase 9 compared with $\beta$-actin is shown (D). ${ }^{\text {ns }} P>0.05,{ }^{*} P<0.05$, ** $P<0.01$ vs the corresponding group.

(Figure 3A-F). Compared with escin treatment, we found that severe DNA damage could be rescued in p62 overexpression and escin treated cells (Figure 3G-J), suggesting that p62 regulates escin-induced DNA damage and has a protective effect in this model. In addition, there were no changes in DNA damage and repair proteins in both the p62 knockdown and overexpression models.

Recent studies have demonstrated that p62 freely shuttles from the cytoplasm to the nucleus and that nuclear-localized p62 increases the sensitivity of tumor cells to radiation ${ }^{[27]}$. In autophagy-defective cells, accumulated p62 directly binds to and inhibits nuclear RNF168, an E3 ligase essential for histone $\mathrm{H} 2 \mathrm{~A}$ ubiquitination and DNA damage responses, which results in the inability of DNA repair proteins, such as BRCA1, RAP80 and Rad51, to recruit to the sites of DNA doublestrand breaks ${ }^{[27]}$. In the absence of autophagy, p62 inhibits DNA repair and histone ubiquitinated degradation. However, there is a contradiction in autophagy integrated cells. Surprisingly, we found that escin apparently increases the autophagy levels in HCT116 and HCT-8 cells (Figure 9A), simultaneously upregulating the expression of p62, which may indicate that RNF168 leads to ubiquitination of DNA repair proteins to recruit them to the sites of DNA damage to repair the damage. In addition, escin apparently increases the levels of cellular ROS and autophagy (Figure 2A, Figure 9A). ROS, which induces autophagy and is also eliminated by autophagy, may be involved in the functions of p62 in escin-induced DNA damage and repair. The detailed mechanisms as to how p62 induces DNA damage repair in escin-treated cells requires further study.

PARP1 is one of the proteins that links DNA damage and apoptosis $^{[47]}$. Apoptosis is induced by inhibition of PARP1 and $\mathrm{EGFR}^{[47]}$. We speculated that severe DNA damage, which was induced by 62 knockdown, was related to escin-induced apoptosis. Escin induced apoptosis (Figure 4) and p62 knockdown augmented escin-induced apoptosis (Figure 5), and there was an antitumor effect of escin in vivo (Figure 7). However, p62 overexpression partly rescued escin-induced cell viability inhibition and cell apoptosis (Figure 6). P62 increased escin-induced apoptosis by augmenting escin-induced DNA damage. The mechanisms involved in this regulation were further investigated. Escin-induced apoptosis was increased when p-ATM was inhibited by KU55933 (Figure 8), suggesting that activation of the ATM pathway is important in causing apoptosis. Our results showed that escin activated ROS levels (Figure 2A), however, there is no evidence to expound the relationship between escin-induced autophagy and apoptosis. Autophagy is a protective factor against DNA damage, ROS and endoplasmic reticulum stress. In response to escininduced oxidative stress, intracellular autophagy level was 
A

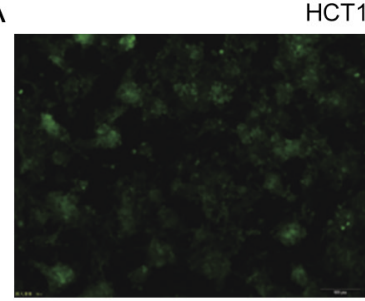

Fluorescence-field (GFP)

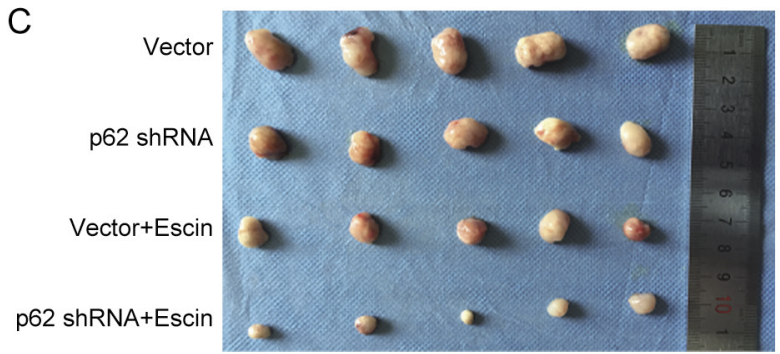

$E$

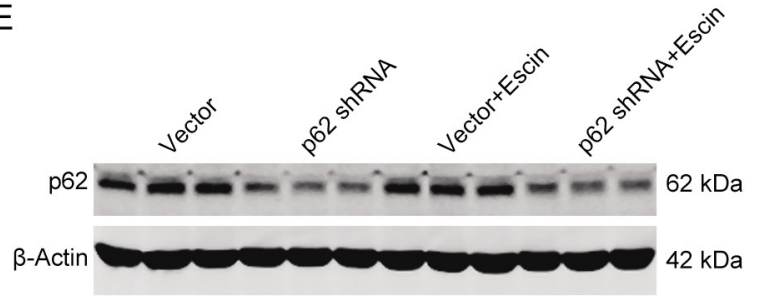

B

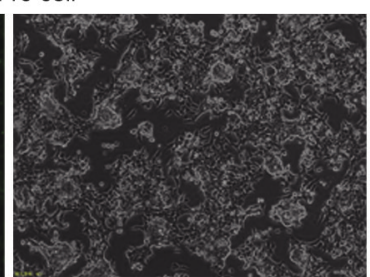

Bright-field
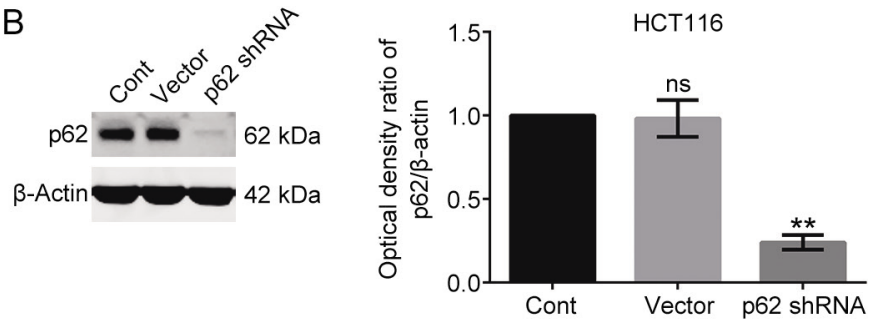

Figure 7. Downregulation of p62 enhanced the antitumor effect of escin in vivo. (A) The transfection efficiency of p62 shRNA in HCT116 cells. Cells were transfected with vector and GFP-p62-shRNA. GFP-green fluorescence was verified with fluorescence microscopy after cells were selected in medium with $4 \mu \mathrm{g} / \mathrm{mL}$ puromycin for 2 weeks. (B) Expression and knockdown efficiency of p62 in control, vector transfection and p62 shRNA transfection cells. (C) Comparison of tumor sizes from various groups $(n=5)$. (D) Comparison of tumor weights from various groups. (E) Expression of p62 in xenograft tumor tissues by Western blotting. ${ }^{n s} P>0.05,{ }^{*} P<0.05,{ }^{* *} P<0.01$ vs the corresponding group.

increased by escin (Figure 9A). Furthermore, knockdown of Atg5 with escin treatment increased escin-induced apoptosis and DNA damage compared with escin treatment alone (Figure 9B, C). These results suggested that escin-induced autophagy played a protective role in escin-induced apoptosis and DNA damage.

In conclusion, this study demonstrated that the signaling adaptor p62 reduced escin-induced apoptosis in CRC cells via p62-mediated DNA damage and the ATM $/{ } \mathrm{H} 2 \mathrm{AX}$ pathway. p62-mediated DNA damage may be a potential target for the antitumor effect of escin.

\section{Acknowledgements}

This work was partially supported by the National Natural Science Foundation of China (No 81672970), the Natural Science Foundation of Jiangsu Province (No BK20160338), and supported by Suzhou Key Medical Center (No LCZX201505), the Projects of Suzhou Technology Bureau (No SS201753, SYS201552, SZS201618), the Second Affiliated Hospital of Soochow University Preponderant Clinic Discipline Group Project Funding, the Project of Invigorating Health Care through Science, Technology and Education (Jiangsu Provincial Medical Youth Talent, QNRC2016249) and Graduate
Student Scientific Research Innovation Projects of Jiangsu Province (No KYCX17_1999), National Natural Science Youth Foundation of China (№ 81602613).

\section{Author contribution}

All of the listed authors contributed to the idea generation, design, and completion of this study. Zhong WANG and Qiang CHEN contributed equally to the idea generation, experimental work and manuscript preparation; Bin LI, Jiaming XIE, Xiao-dong YANG, Kui ZHAO, Yong WU, Zhen-yu $Y E$, and Zheng-rong CHEN contributed to the experimental work and manuscript preparation; Chun-gen XING and Zheng-hong QIN guided the idea generation, experimental work and manuscript preparation. All of the authors reviewed the manuscript.

\section{References}

1 Torre LA, Bray F, Siegel RL, Ferlay J, Lortet-Tieulent J, Jemal A. Global cancer statistics, 2012. CA Cancer J Clin 2015; 65: 87-108.

2 Siegel R, Desantis C, Jemal A. Colorectal cancer statistics, 2014. CA Cancer J Clin 2014; 64: 104-17.

3 Siegel RL, Miller KD, Fedewa SA, Ahnen DJ, Meester RGS, Barzi A, et al. Colorectal cancer statistics, 2017. CA Cancer J Clin 2017; 67: 
A

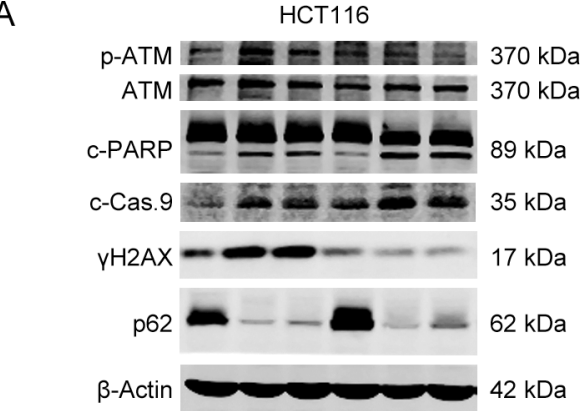

Scramble siRNA $+-\quad+-$ p62 siRNA1 - + - ++

p62 siRNA2 - $-+{ }_{-}+$

Escin $60 \mu \mathrm{g} / \mathrm{mL}++++++$

ATM inhibitor $-c_{-}+++$
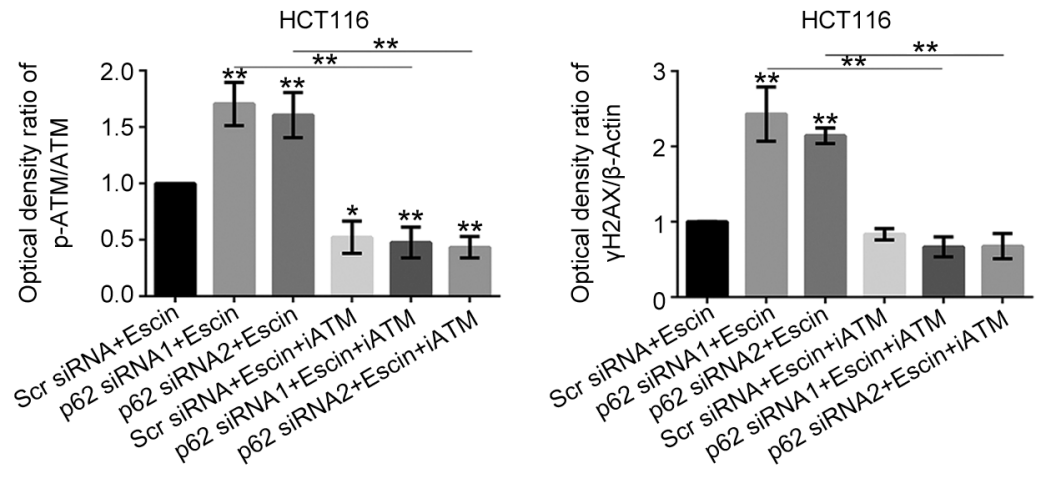

HCT116
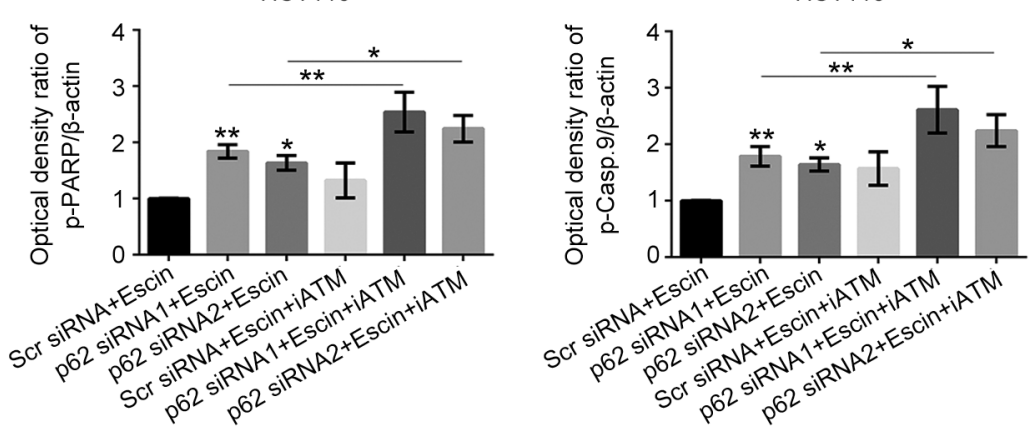

B

HCT8

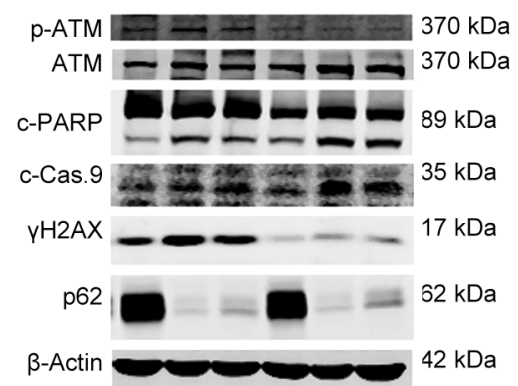

Scramble siRNA $+-\ldots+-$

p62 siRNA1 - + - ++-

p62 siRNA2 - $-+{ }_{-}+$

Escin $60 \mu \mathrm{g} / \mathrm{mL}++++++$

ATM inhibitor $--_{-}+++$
HCT8
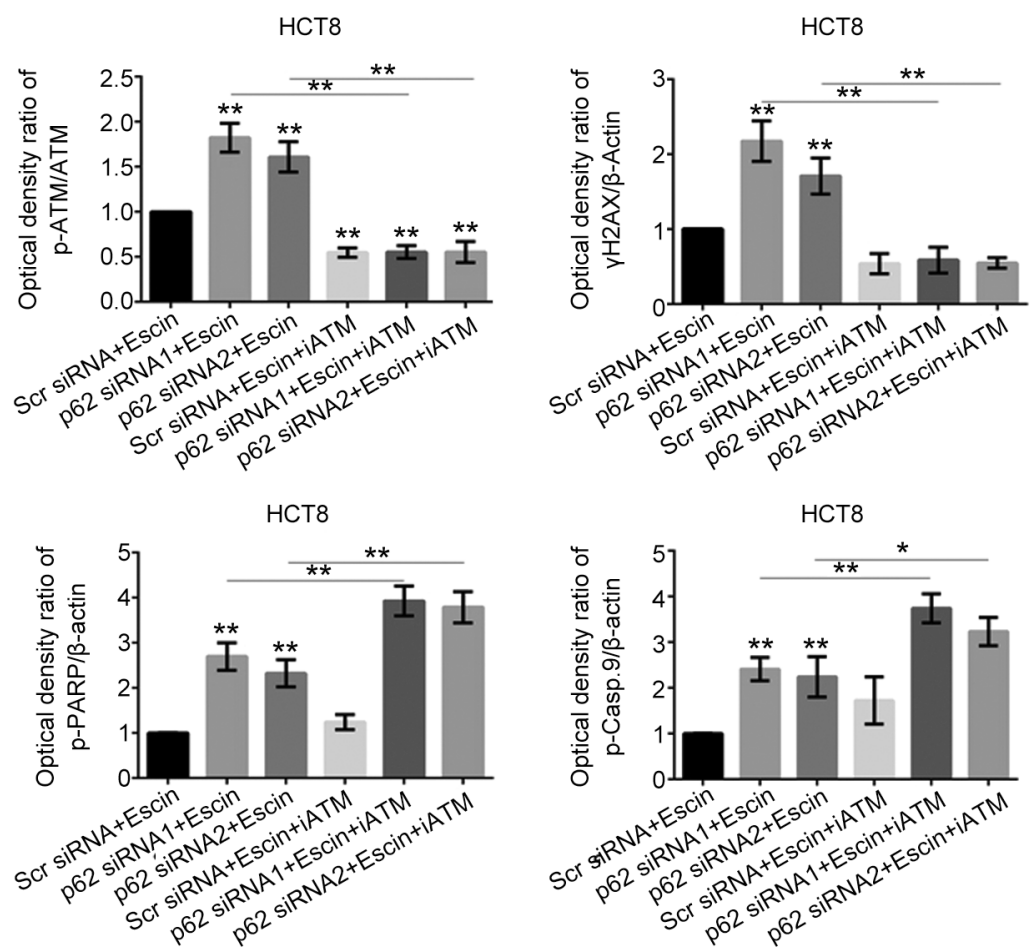

Figure 8A-B. p62 regulation of the ATM/YH2AX pathway was involved in escin-induced DNA damage and apoptosis. (A, B) p62 knockdown combined with the ATM inhibitor KU55933 increased DNA damage and cell apoptosis. Cells were transfected with scramble siRNA or p62 siRNA1/2, and after 36 h, cells were treated with $10 \mu \mathrm{mol} / \mathrm{L}$ KU55933 for $2 \mathrm{~h}$ before escin treatment for $12 \mathrm{~h}$. Protein levels of p-ATM, ATM, cleaved-PARP, cleaved-caspase 9 , $\mathrm{YH} 2 \mathrm{AX}$, p62 and $\beta$-actin were detected by Western blotting. Down: quantitative analysis of the optical density ratio of p-ATM, $\mathrm{YH} 2 \mathrm{AX}$, cleaved-PARP and cleaved-caspase 9 compared with $\beta$-actin are shown. ${ }^{*} P<0.05,{ }^{* *} P<0.01$. 
C

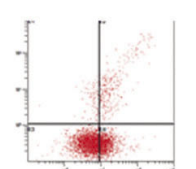

Scramble siRNA + Escin

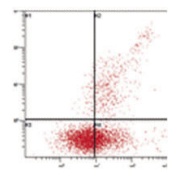

Scramble siRNA + Escin+iATM

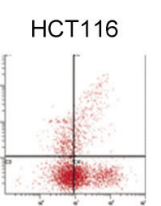

p62 siRNA1

+ Escin

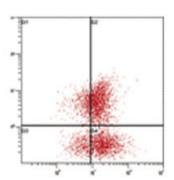

p62 siRNA1

+ Escin+iATM

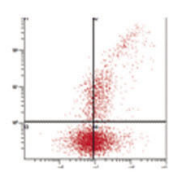

p62 siRNA2 + Escin

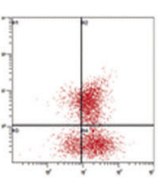

p62 siRNA2 + Escin+iATM

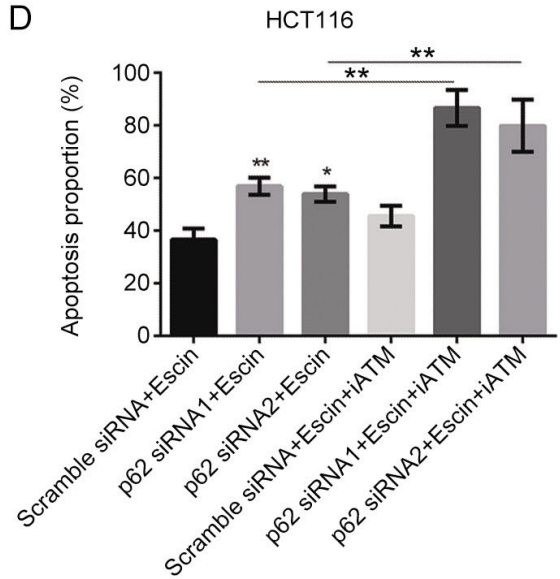

Figure 8C-D. p62 regulation of the ATM/YH2AX pathway was involved in escin-induced DNA damage and apoptosis. (C) Analysis of apoptosis with FACS in HCT116 cells. Cells were treated as described above, and apoptosis was analyzed with FACS. Quantitative analysis of apoptosis after p62 knockdown and escin with or without KU55933 is shown (D). ${ }^{\text {ns }} P>0.05,{ }^{*} P<0.05,{ }^{* *} P<0.01$ vs the corresponding group.

177-93.

4 Holohan C, Van Schaeybroeck S, Longley DB, Johnston PG. Cancer drug resistance: an evolving paradigm. Nat Rev Cancer 2013; 13: 714-26.

5 Fletcher JI, Williams RT, Henderson MJ, Norris MD, Haber M. ABC transporters as mediators of drug resistance and contributors to cancer cell biology. Drug Resist Updat 2016; 26: 1-9.

6 Fojo T, Bates S. Strategies for reversing drug resistance. Oncogene 2003; 22: 7512-23.

7 Wu Q, Yang Z, Nie Y, Shi Y, Fan D. Multi-drug resistance in cancer chemotherapeutics: mechanisms and lab approaches. Cancer Lett 2014; 347: 159-66.

8 Diehm C, Trampisch HJ, Lange S, Schmidt C. Comparison of leg compression stocking and oral horse-chestnut seed extract therapy in patients with chronic venous insufficiency. Lancet 1996; 347: 292-4.

9 Pittler MH, Ernst E. Horse chestnut seed extract for chronic venous insufficiency. Cochrane Database Syst Rev 2012; 11: CD003230.

10 Shen DY, Kang JH, Song W, Zhang WQ, Li WG, Zhao Y, et al. Apoptosis of human cholangiocarcinoma cell lines induced by beta-escin through mitochondrial caspase-dependent pathway. Phytother Res 2011; 25: 1519-26.

11 Guney G, Kutlu HM, Iscan A. The apoptotic effects of escin in the H-Ras transformed 5RP7 cell line. Phytother Res 2013; 27: 900-5.

12 Mojzisova G, Kello M, Pilatova M, Tomeckova V, Vaskova J, Vasko L, et al. Antiproliferative effect of beta-escin-an in vitro study. Acta Biochim Pol 2016; 63: 79-87.

13 Ciftci GA, Iscan A, Kutlu M. Escin reduces cell proliferation and induces apoptosis on glioma and lung adenocarcinoma cell lines. Cytotechnology 2015; 67: 893-904.

14 Rimmon A, Vexler A, Berkovich L, Earon G, Ron I, Lev-Ari S. Escin chemosensitizes human pancreatic cancer cells and inhibits the nuclear factor-kappab signaling pathway. Biochem Res Int 2013; 2013: 251752.

15 Yuan SY, Cheng CL, Wang SS, Ho HC, Chiu KY, Chen CS, et al. Escin induces apoptosis in human renal cancer cells through $\mathrm{G}_{2} / \mathrm{M}$ arrest and reactive oxygen species-modulated mitochondrial pathways. Oncol Rep 2017; 37: 1002-10.

16 Harford-Wright E, Bidere N, Gavard J. Beta-escin selectively targets the glioblastoma-initiating cell population and reduces cell viability.
Oncotarget 2016; 7: 66865-79.

17 Patlolla JM, Qian L, Biddick L, Zhang Y, Desai D, Amin S, et al. BetaEscin inhibits NNK-induced lung adenocarcinoma and ALDH1A1 and RhoA/Rock expression in $\mathrm{A} / \mathrm{J}$ mice and growth of $\mathrm{H} 460$ human lung cancer cells. Cancer Prev Res (Phila) 2013; 6: 1140-9.

18 Wang YW, Wang SJ, Zhou YN, Pan SH, Sun B. Escin augments the efficacy of gemcitabine through down-regulation of nuclear factorkappaB and nuclear factor-kappaB-regulated gene products in pancreatic cancer both in vitro and in vivo. J Cancer Res Clin Oncol 2012; 138: 785-97.

19 Ming ZJ, Hu Y, Qiu YH, Cao L, Zhang XG. Synergistic effects of betaaescin and 5-fluorouracil in human hepatocellular carcinoma SMMC7721 cells. Phytomedicine 2010; 17: 575-80.

20 Moscat J, Diaz-Meco MT. p62 at the crossroads of autophagy, apoptosis, and cancer. Cell 2009; 137: 1001-4.

21 Ren F, Shu G, Liu G, Liu D, Zhou J, Yuan L, et al. Knockdown of p62/ sequestosome 1 attenuates autophagy and inhibits colorectal cancer cell growth. Mol Cell Biochem 2014; 385: 95-102.

22 Thompson HG, Harris JW, Wold BJ, Lin F, Brody JP. p62 overexpression in breast tumors and regulation by prostate-derived Ets factor in breast cancer cells. Oncogene 2003; 22: 2322-33.

23 Rolland P, Madjd Z, Durrant L, Ellis IO, Layfield R, Spendlove I. The ubiquitin-binding protein p62 is expressed in breast cancers showing features of aggressive disease. Endocr Relat Cancer 2007; 14: 7380.

24 Inoue D, Suzuki T, Mitsuishi Y, Miki Y, Suzuki S, Sugawara S, et al. Accumulation of p62/SQSTM1 is associated with poor prognosis in patients with lung adenocarcinoma. Cancer Sci 2012; 103: 760-6.

25 Nakayama S, Karasawa H, Suzuki T, Yabuuchi S, Takagi K, Aizawa T, et al. p62/sequestosome 1 in human colorectal carcinoma as a potent prognostic predictor associated with cell proliferation. Cancer Med 2017; 6: 1264-74.

26 Yu H, Su J, Xu Y, Kang J, Li H, Zhang L, et al. p62/SQSTM1 involved in cisplatin resistance in human ovarian cancer cells by clearing ubiquitinated proteins. Eur J Cancer 2011; 47: 1585-94.

27 Wang Y, Zhang N, Zhang L, Li R, Fu W, Ma K, et al. Autophagy regulates chromatin ubiquitination in dna damage response through elimination of SQSTM1/p62. Mol Cell 2016; 63: 34-48.

28 Xu LZ, Li SS, Zhou W, Kang ZJ, Zhang QX, Kamran M, et al. p62/ 
A

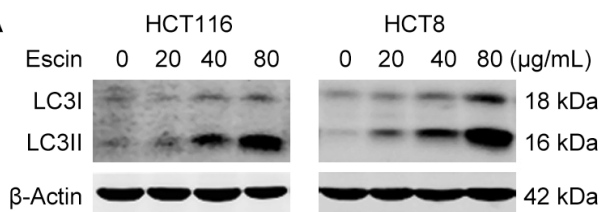

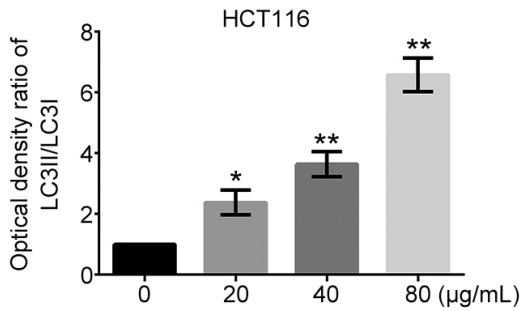
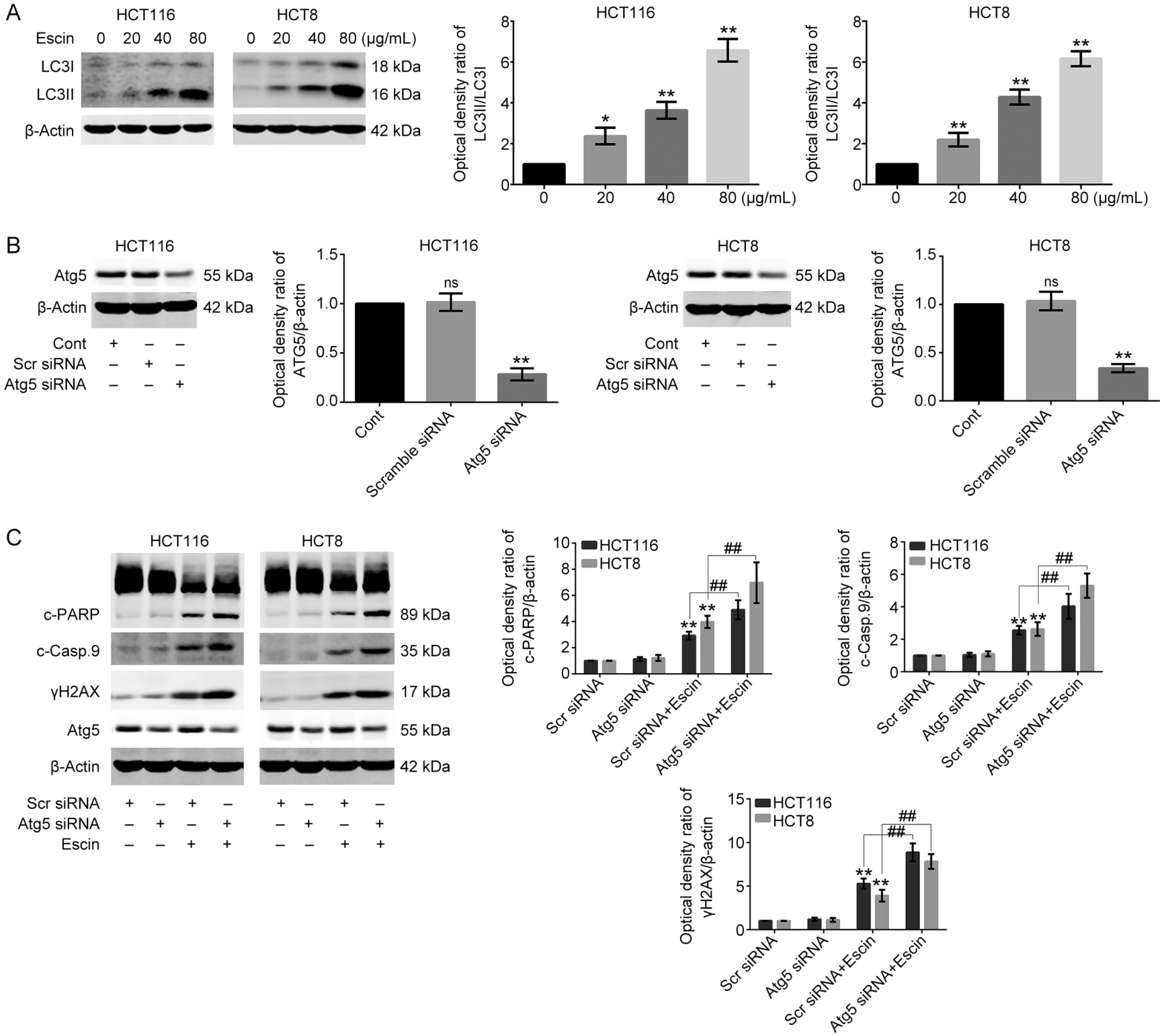

Figure 9. Escin activated autophagy and inhibition of autophagy augmented escin-induced apoptosis. (A) Escin activated autophagy. HCT116 and HCT8 cells were treated with different concentrations of escin for $12 \mathrm{~h}$, the level of autophagy was detected by Western blot. Right: the quantitative analysis of the optical density ratio of LC3 compared with the loading control ( $\beta$-actin) in HCT116 and HCT8. (B) Knockdown efficiency of Atg5 in HCT116 and HCT8 cells. Cells were transiently transfected with scramble siRNA and Atg5 siRNA for $36 \mathrm{~h}$. The level of Atg 5 was tested by Western blot. Right: the quantitative analysis of the optical density ratio of Atg 5 compared with $\beta$-actin is shown. (C) Expression of $\mathrm{yH} 2 \mathrm{AX}$ and apoptosis related proteins after Atg5 knockdown with escin treatment. Cells were treated with $60 \mu \mathrm{g} / \mathrm{mL}$ escin for $12 \mathrm{~h}$ after scramble siRNA and Atg5 siRNA transfection for $36 \mathrm{~h}$. The protein levels of $\mathrm{yH} 2 \mathrm{AX}$, cleaved-PARP, cleaved-caspase 9 and $\beta$-actin were detected by Western blot. Right: the quantitative analysis of the optical density ratio of $\mathrm{YH} 2 \mathrm{AX}$, cleaved-PARP, cleaved-caspase 9 compared with $\beta$-actin is shown. ${ }^{* *} P<0.01 .{ }^{\# \#} P<0.01$.

SQSTM1 enhances breast cancer stem-like properties by stabilizing MYC mRNA. Oncogene 2017; 36: 304-17.

29 Guo D, Ying Z, Wang H, Chen D, Gao F, Ren H, et al. Regulation of autophagic flux by CHIP. Neurosci Bull 2015; 31: 469-79.

30 Mathew R, Karp CM, Beaudoin B, Vuong N, Chen G, Chen HY, et al. Autophagy suppresses tumorigenesis through elimination of p62. Cell 2009; 137: 1062-75.

31 Duran A, Linares JF, Galvez AS, Wikenheiser K, Flores JM, Diaz-Meco MT, et al. The signaling adaptor p62 is an important NF-kappaB mediator in tumorigenesis. Cancer Cell 2008; 13: 343-54.

32 Lage $\mathrm{H}$. An overview of cancer multidrug resistance: a still unsolved problem. Cell Mol Life Sci 2008; 65: 3145-67.

33 Ren F, Shen J, Shi H, Hornicek FJ, Kan Q, Duan Z. Novel mechanisms and approaches to overcome multidrug resistance in the treatment of ovarian cancer. Biochim Biophys Acta 2016; 1866: 266-75.

34 Patlolla JM, Raju J, Swamy MV, Rao CV. Beta-escin inhibits colonic aberrant crypt foci formation in rats and regulates the cell cycle growth by inducing p21(waf1/cip1) in colon cancer cells. Mol Cancer 
Ther 2006; 5: 1459-66.

35 Huang GL, Shen DY, Cai CF, Zhang QY, Ren HY, Chen QX. Beta-escin reverses multidrug resistance through inhibition of the GSK3beta/ beta-catenin pathway in cholangiocarcinoma. World J Gastroenterol 2015; 21: 1148-57.

36 Niu YP, Li LD, Wu LM. Beta-aescin: a potent natural inhibitor of proliferation and inducer of apoptosis in human chronic myeloid leukemia K562 cells in vitro. Leuk Lymphoma 2008; 49: 1384-91.

37 Zhang Z, Gao J, Cai X, Zhao Y, Wang Y, Lu W, et al. Escin sodium induces apoptosis of human acute leukemia Jurkat T cells. Phytother Res 2011; 25: 1747-55.

38 Tan SM, Li F, Rajendran P, Kumar AP, Hui KM, Sethi G. Identification of beta-escin as a novel inhibitor of signal transducer and activator of transcription 3/Janus-activated kinase 2 signaling pathway that suppresses proliferation and induces apoptosis in human hepatocellular carcinoma cells. J Pharmacol Exp Ther 2010; 334: 285-93.

39 Harikumar KB, Sung B, Pandey MK, Guha S, Krishnan S, Aggarwal BB. Escin, a pentacyclic triterpene, chemosensitizes human tumor cells through inhibition of nuclear factor-kappaB signaling pathway. Mol Pharmacol 2010; 77: 818-27.

40 Roos WP, Kaina B. DNA damage-induced cell death by apoptosis.
Trends Mol Med 2006; 12: 440-50.

41 Chipuk JE, Green DR. Dissecting p53-dependent apoptosis. Cell Death Differ 2006; 13: 994-1002.

42 Bonner WM, Redon CE, Dickey JS, Nakamura AJ, Sedelnikova OA, Solier S, et al. GammaH2AX and cancer. Nat Rev Cancer 2008; 8: 957-67.

43 Burma S, Chen BP, Murphy M, Kurimasa A, Chen DJ. ATM phosphorylates histone $\mathrm{H} 2 \mathrm{AX}$ in response to DNA double-strand breaks. J Biol Chem 2001; 276: 42462-7.

44 Gilardini Montani MS, Prodosmo A, Stagni V, Merli D, Monteonofrio L, Gatti V, et al. ATM-depletion in breast cancer cells confers sensitivity to PARP inhibition. J Exp Clin Cancer Res 2013; 32: 95.

45 Weston VJ, Oldreive CE, Skowronska A, Oscier DG, Pratt G, Dyer MJ, et al. The PARP inhibitor olaparib induces significant killing of ATMdeficient lymphoid tumor cells in vitro and in vivo. Blood 2010; 116: 4578-87.

46 Williamson CT, Muzik H, Turhan AG, Zamo A, O'Connor MJ, Bebb DG, et al. ATM deficiency sensitizes mantle cell lymphoma cells to poly(ADP-ribose) polymerase-1 inhibitors. Mol Cancer Ther 2010; 9: 347-57.

47 Luo X, Kraus WL. On PAR with PARP: cellular stress signaling through poly(ADP-ribose) and PARP-1. Genes Dev 2012; 26: 417-32. 